\title{
De Félix Martin-Sabon à Pierre Pradel, une histoire de plaques de verre
}

Archives patrimoniales de la photothèque de l'École du Louvre

From Félix Martin-Sabon to Pierre Pradel, a history of glass plates. Heritage

archives from the École du Louvre photographic library

\section{Anne-Bénédicte Mérel-Brandenburg}

\section{OpenEdition Journals}

Édition électronique

URL : http://journals.openedition.org/cel/938

DOI : $10.4000 /$ cel.938

ISSN : 2262-208X

Éditeur

École du Louvre

\section{Référence électronique}

Anne-Bénédicte Mérel-Brandenburg, « De Félix Martin-Sabon à Pierre Pradel, une histoire de plaques de verre ", Les Cahiers de l'École du Louvre [En ligne], 12 | 2018, mis en ligne le 03 mai 2018, consulté le 17 septembre 2019. URL : http://journals.openedition.org/cel/938 ; DOI : 10.4000/cel.938

Ce document a été généré automatiquement le 17 septembre 2019.

\section{(c) $(1) \odot$}

Les Cahiers de l'École du Louvre sont mis à disposition selon les termes de la licence Creative Commons Attribution - Pas d'Utilisation Commerciale - Pas de Modification 4.0 International. 


\title{
De Félix Martin-Sabon à Pierre Pradel, une histoire de plaques de
} verre

\author{
Archives patrimoniales de la photothèque de l'École du Louvre \\ From Félix Martin-Sabon to Pierre Pradel, a history of glass plates. Heritage \\ archives from the École du Louvre photographic library
}

Anne-Bénédicte Mérel-Brandenburg

\section{NOTE DE L'AUTEUR}

À la lecture des archives, Félix Martin-Sabon fut le premier à faire un don de plaques de verre à l'École du Louvre (AN/AMN F21: 21 janvier 1903) et Pierre Pradel fut le dernier à commander des plaques de verre (Arch/EDL : carnet de commande décembre 1960).

1 Au tournant des $\mathrm{XIX}^{\mathrm{e}}$ et $\mathrm{Xx}^{\mathrm{e}}$ siècles, l'enseignement académique fut profondément transformé par l'adoption de nouveaux procédés pédagogiques en rapport étroit avec les progrès de la photographie et leur diffusion. L'École du Louvre et ses professeurs, au même titre que leurs confrères universitaires, participèrent pleinement à cette innovation, l'enseignement de l'archéologie, de l'histoire de l'art et de la muséologie par l'image, image qui eut un rôle capital dans le débat de l'histoire de l'art. Dès lors, les plaques de verre, supports privilégiés, acquièrent une valeur pédagogique, générant un nouveau type de discours inductif et comparatif, analysé depuis quelques années par le développement de nouvelles disciplines (l'histoire de l'histoire de l'art et de l'histoire de l'archéologie) et deviennent objets d'étude en tant que photographies historiques. De cette époque pionnière, l'École du Louvre conserve au sein des services documentaires des richesses patrimoniales composées de photographies, de cartes postales, de positifs et négatifs sur plaque de verre, de formats différents, supplantés par les diapositives, puis par les images numériques, regroupées dans les espaces de la photothèque. Ces collections retracent en majorité l'enseignement dispensé depuis plus 
de cent vingt ans et précisent les supports pédagogiques utilisés et mis à la disposition des professeurs, le contenu des cours dispensés, la connaissance et l'état du patrimoine artistique à travers le temps. Si les diapositives et les images numériques relèvent d'une mémoire collective récente et actuelle, des points d'ombre subsistaient sur les collections de plaques de verre qu'éclairent partiellement les documents écrits ${ }^{1}$ publiés $^{2}$ et les archives ${ }^{3}$ parfois inédites ${ }^{4}$.

\section{Création et itinéraire d'une photothèque dans le palais du Louvre}

2 Depuis sa création en 1882, l'École du Louvre connut des emplacements divers au sein du Palais du Louvre (fig. 1). Elle occupa dans un premier temps le salon du grand appartement du général Fleury, grand écuyer de Napoléon III, sur la cour Caulaincourt, actuelle cour Lefuel. La salle à manger était affectée à la bibliothèque, et le salon accueillait les élèves et les auditeurs groupés autour de la grande table ovale devant laquelle siégeait le professeur. Ce salon pouvait accueillir 200 personnes assises et une centaine debout (fig. 2).

Fig. 1

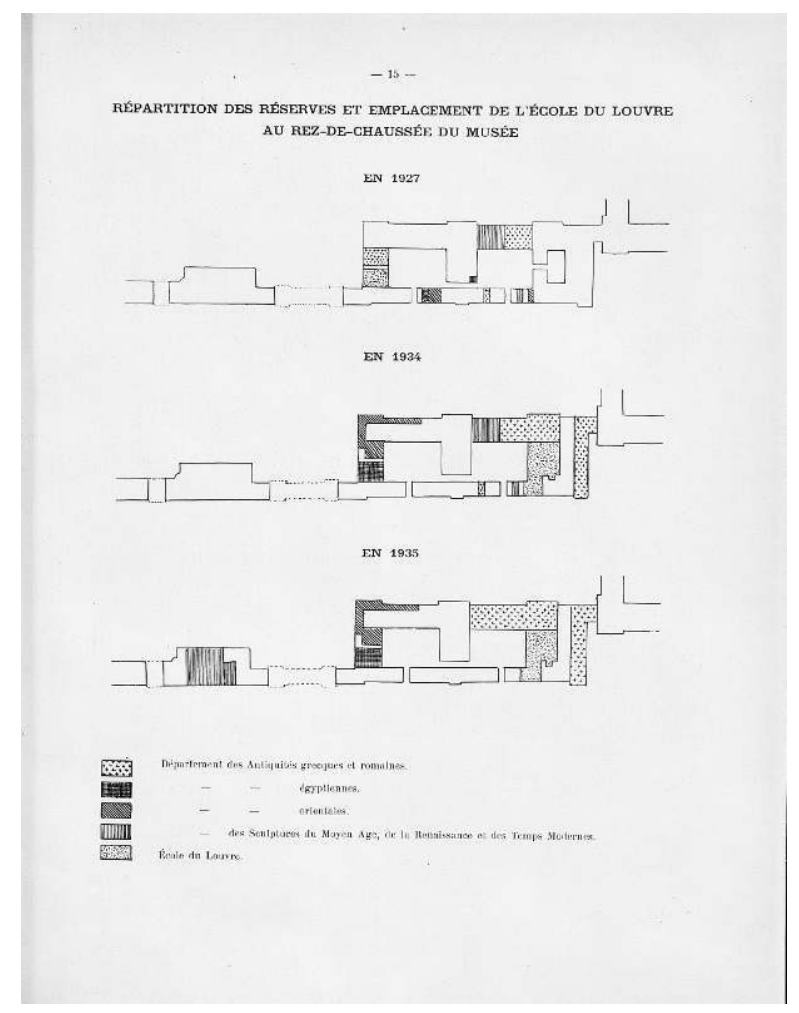

Emplacement de l'École du Louvre 1927-1938, d'après Bulletin des Musées de France, 1934-01, janvier 1934, p. 15

SOURCE GALLICA.BNF.FR / BNF 
Fig. 2

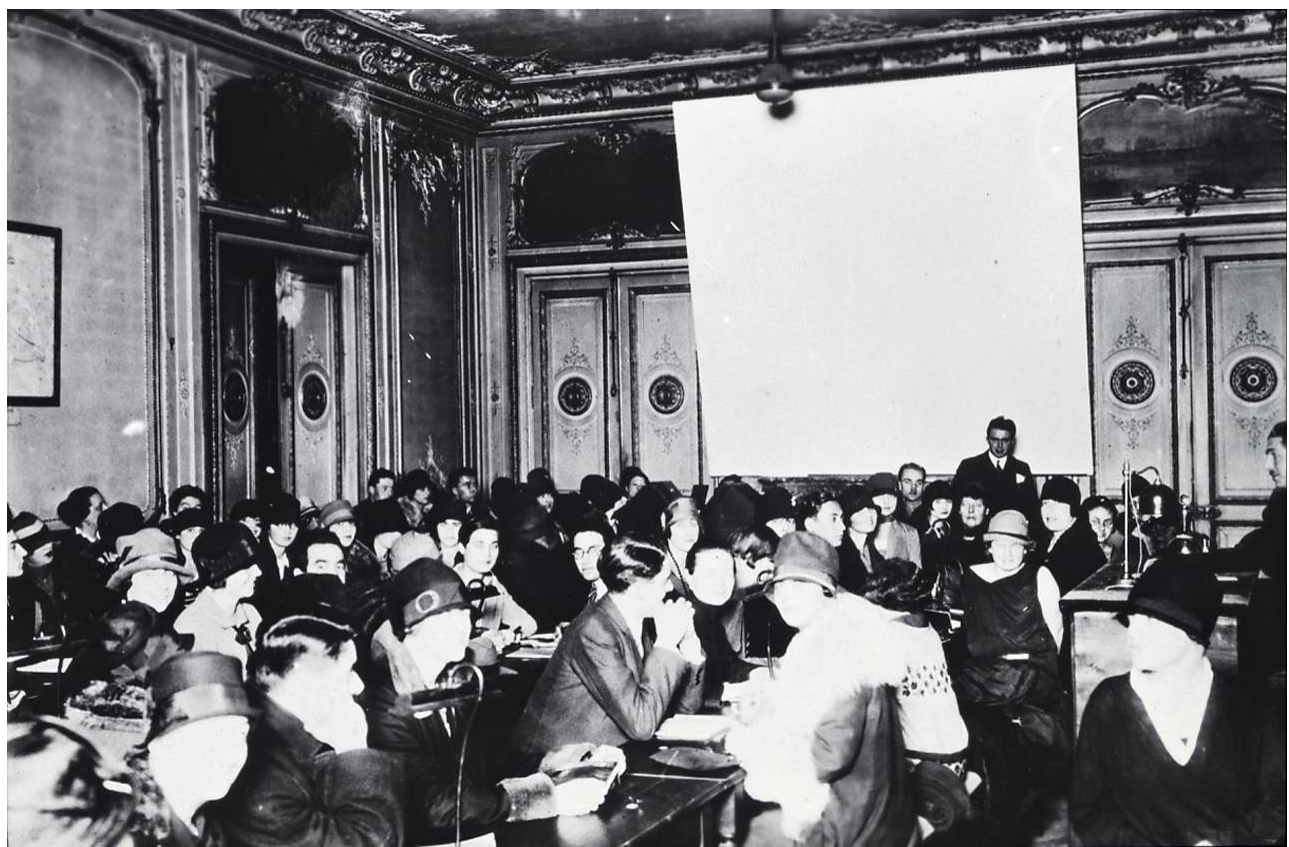

Cours dans le salon du grand appartement du général Fleury

Arch/EDL

Nulle mention, dans cette installation qui devait durer jusqu'à la fin des années 1920, soit près de cinquante ans, d'un lieu réservé à une photothèque. Le salon du général Fleury fut abandonné en 1929 pour une nouvelle salle de cours aménagée grâce à la générosité de H.W.G. Mortland au rez-de-chaussée de la cour Lefuel, avant que l'École ne bénéficie en 1932-1933, dans le cadre des grands travaux de modernisation menés par Henri Verne, directeur des Musées nationaux et de l'École du Louvre, de locaux entièrement rénovés dans l'aile Nord de la cour Visconti ${ }^{5}$ (fig. 1). Elle fut dotée de deux salles de cours, l'amphithéâtre Courajod et la salle Pottier, accueillant respectivement 670 et 90 élèves, de "sept locaux de service ${ }^{6}$ ", " quatre bureaux de professeurs et de secrétaires, bibliothèque, large antichambre où se font face le vestiaire et le service des inscriptions, commodités. Une salle de lecture et une salle d'étude sont en projet et recevront [...] les adhérents d'une association des élèves ${ }^{7}$ " (fig. 3). Ce fut dans ce contexte que naquit une "clichothèque " qui partagea jusqu'en 1938 l'espace de vente des cours sténographiés ${ }^{8}$, puis conquit un local d'une vingtaine de mètres carrés, aéré par un soupirail grillagé donnant sur le quai (fig. 4). La photothèque y resta près de trente-cinq ans, avant de monter en 1972 dans les locaux affectés à l'École au premier étage de l'aile du Louvre du "Bord de l'Eau», avec vues sur la cour Visconti et sur la Seine, et y occuper quelques mètres carrés supplémentaires (fig. 5). 
Fig. 3

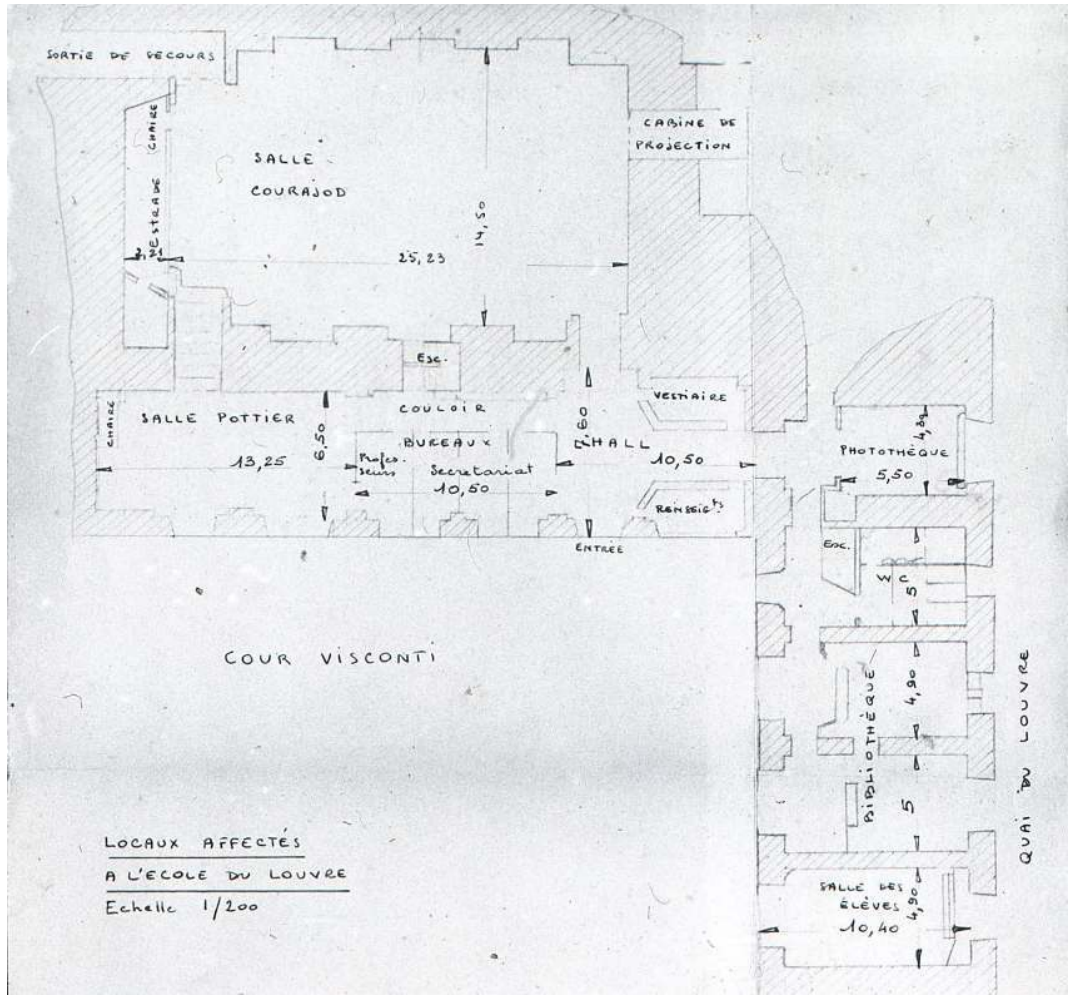

Plan des locaux occupés par l'École du Louvre après son installation cour Visconti (1932-1933) Arch/EDL

Fig. 4

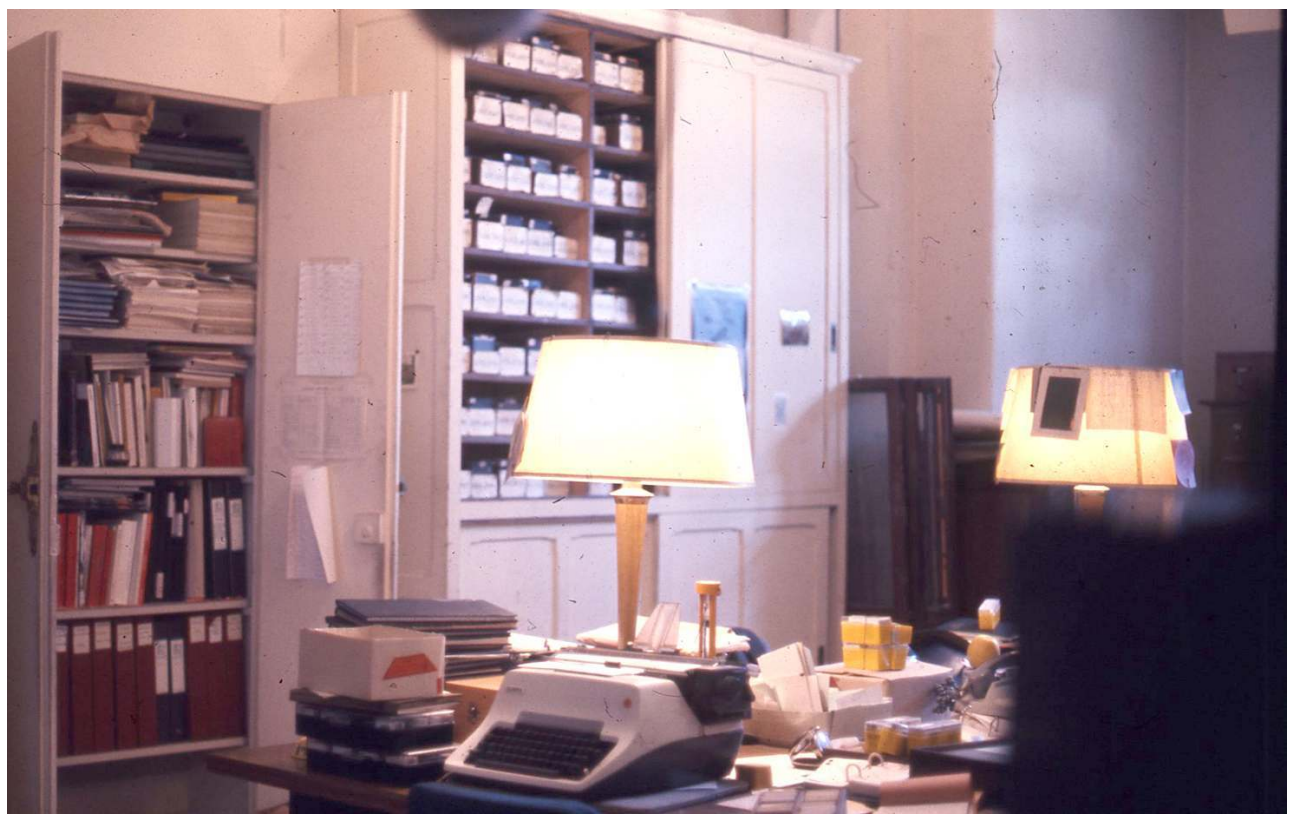

La photothèque, rez-de-chaussée de la cour Visconti (1940-1972) ARCH/EDL 
Fig. 5

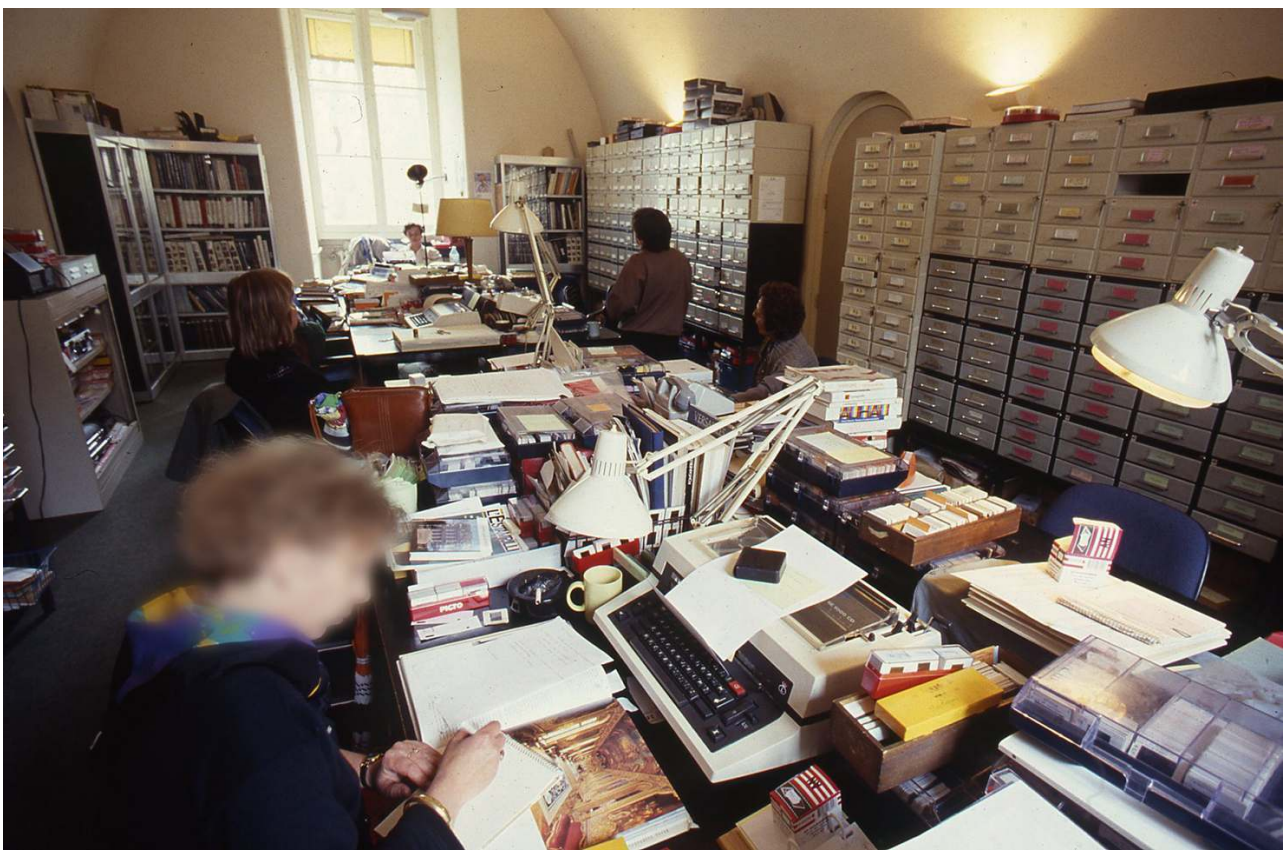

La photothèque, galerie du bord de l'eau (1972-1990)

Arch/EDL

Le service se déploya fin 1990, grâce à la mise à la disposition par l'École d'une surface de près de 100 mètres carrés dans l'un des deux bâtiments préfabriqués situés dans les jardins des Tuileries à proximité de la porte Jaujard. Un dernier déménagement eut lieu en avril 1998, dans les espaces actuels de l'aile de Flore (fig. 6). Les plaques de verre, cartes postales et photographies encore entreposées dans différents endroits des anciens locaux $\mathrm{du}$ « 34, quai du Louvre » furent rassemblées dans une salle d'archives au sein du service. Les plaques de verre pour une partie furent transportées dans des meubles métalliques. Ce mobilier professionnel avait été repéré dans les années 1980 par Luce Lanfranchi, secrétaire générale de l'École, dans les ateliers du Louvre, pour ranger le petit matériel, et commandé à son initiative ${ }^{9}$. La hauteur des tiroirs et leur intérieur modulable s'adaptaient parfaitement au rangement et au format des plaques de verre $8 \frac{1}{2} \times 10$. Robustes, résistants, ces meubles protégeaient les plaques, bien calées, des secousses et des coups (fig. 7). Les plaques conditionnées dans des boîtes en bois (fig.8), et celles rapportées, vers 2000, par l'un des membres du département des Antiquités grecques, étrusques et romaines, furent inventoriées ${ }^{10}$, déposées dans les tiroirs de métal en respectant le classement initial. La continuité historique de la documentation fut ainsi restituée. 
Fig. 6

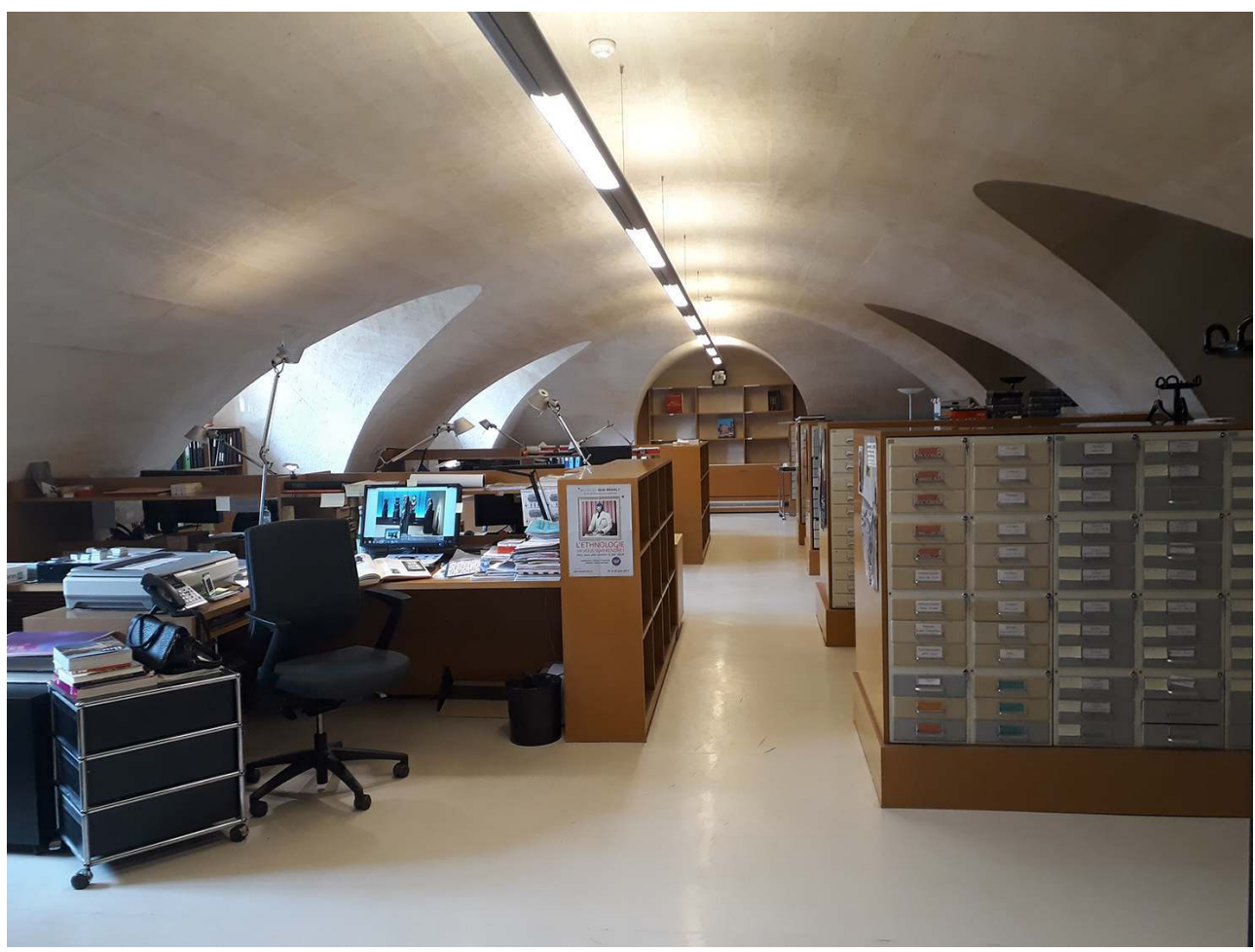

La photothèque dans l'aile de Flore (1998)

\section{ARCH/EDL}

Fig. 7

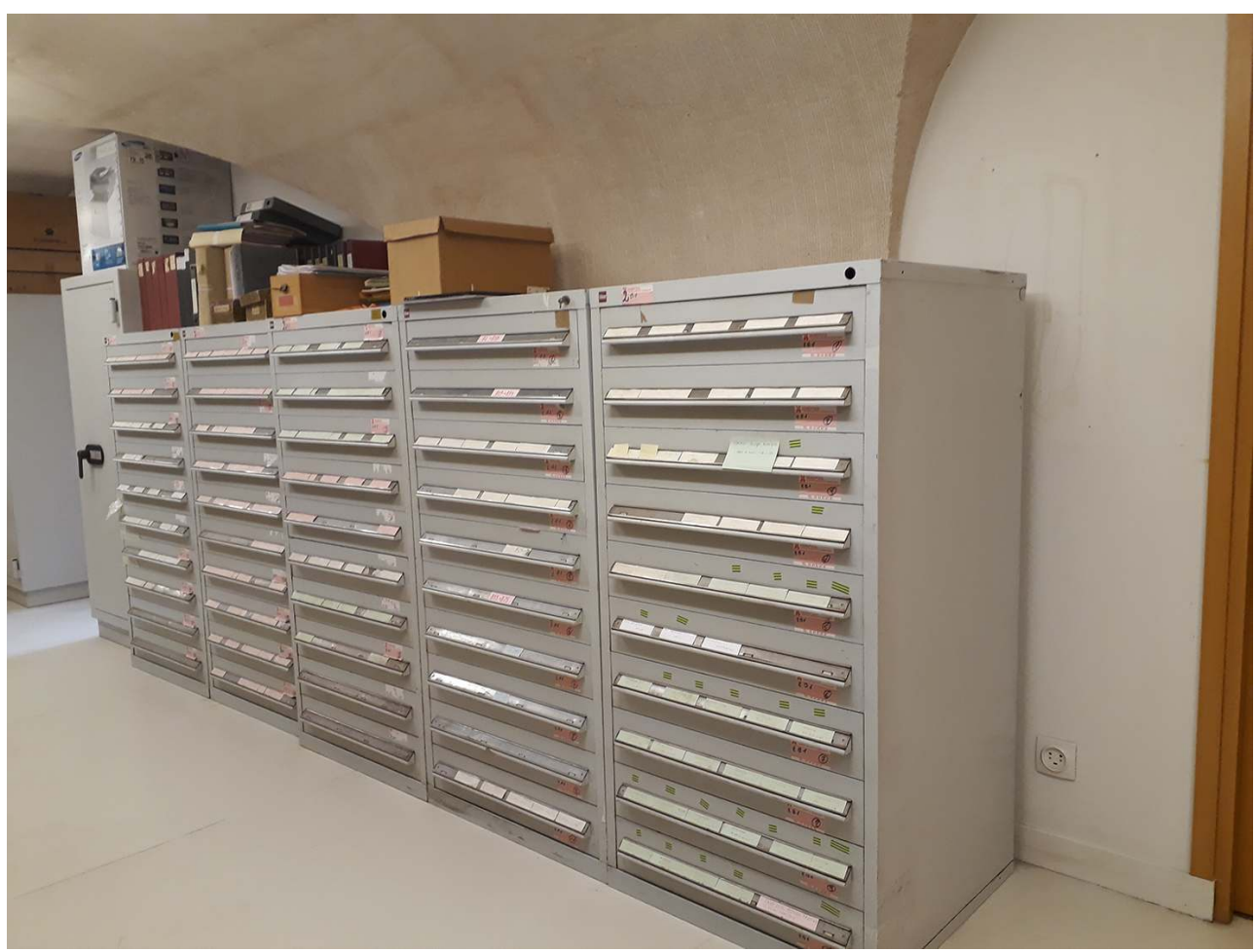

Les meubles métalliques, services documentaires de l'École du Louvre (2018) Arch/EDL 
Fig. 8

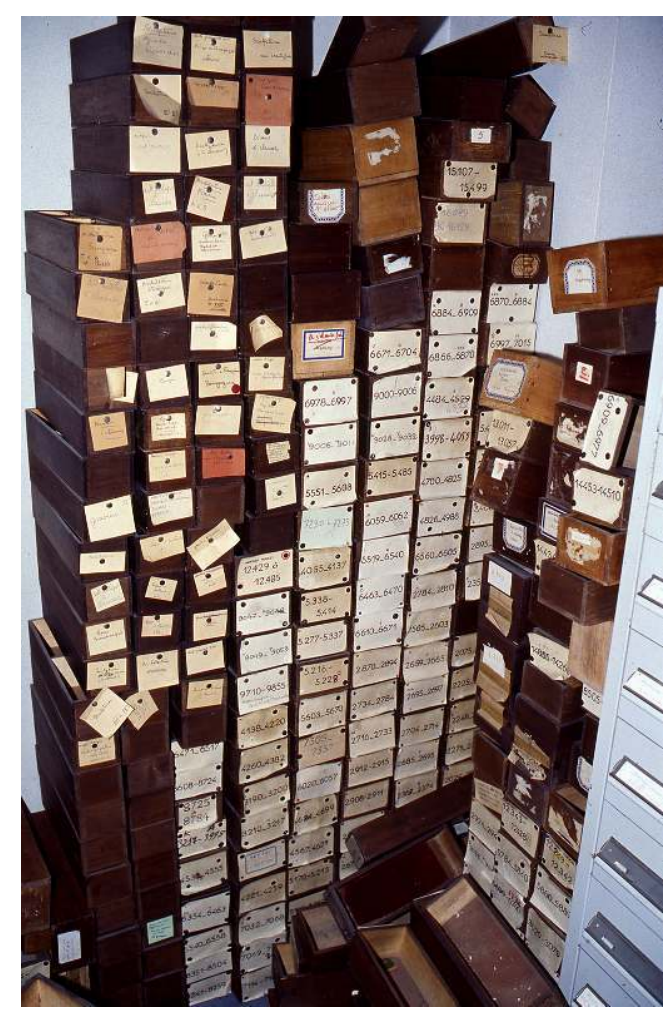

Les boîtes en bois contenant les plaques

Arch/EDL

\section{Regain d'intérêt dans les années 2010}

L'importance de cette documentation, reflet de l'enseignement, de l'état des connaissances et des œuvres des dernières décennies du XIX ${ }^{e}$ siècle aux années 1960, avant que les diapositives ne supplantent les plaques de verre, conduisit, en 1981, à transposer les plaques de verre en diapositives ${ }^{11}$. Les fonds privilégiés furent l'architecture et la sculpture médiévale, l'archéologie et la muséologie. Un premier récolement partiel fut effectué en 1994 dans l'espace du serveur attenant à la salle de documentation installée dans le préfabriqué ${ }^{12}$.

En 2010, la préoccupation constante de conquérir des espaces pour héberger des bureaux ou de repenser la configuration des services documentaires pour un meilleur accueil des élèves menaça les magasins d'archives et par là même les plaques de verre, les photographies et les cartes postales. Dès lors, le devenir de ces archives était mis en question. Une première consultation auprès du directeur de la Médiathèque de l'architecture et du patrimoine (MAP) se révéla négative ${ }^{13}$. Sans examen préalable du fonds et sans prendre en compte la singularité patrimoniale et pédagogique de cet ensemble photographique, constitué, à ses dires, de doublons et de reproductions d'ouvrages, les plaques de verre ne présentaient aucun intérêt pour rejoindre les collections du fort de Saint-Cyr et étaient destinées à la casse ${ }^{14}$. Face à cette position sans appel, en 2011, sur les conseils de Corinne Jouys-Barbelin ${ }^{15}$, la Mission photographique du ministère de la Culture fut sollicitée et procéda à une expertise ${ }^{16}$. 
Ainsi furent mises en évidence leur diversité et l'existence de pièces d'exception pour l'histoire de la photographie et des musées. Quatre-vingt-seize négatifs sous verre contenus dans cinq boîtes de format $24 \times 30$ et cinquante-neuf négatifs dans trois boîtes de format $18 \times 24$ ont particulièrement retenu l'attention. Les boîtes portaient le nom de Lestrange (fig. 9), et les négatifs reproduisaient des salles du Louvre, des œuvres conservées aux départements des Sculptures (fig. 10), des Antiquités orientales, grecques, étrusques et romaines et une "gypsothèque d'antiques" (fig. 11), photographiées par le comte Henry de Lestrange (1853-1926). Administrateur des compagnies d'assurances Le Soleil et L'Aigle, conseiller général de la Charente, il fut également photographe amateur. Il adhéra à plusieurs "sociétés d'amateurs de photographie » et, à ce titre, fut présent dans des salons photographiques de 1902 à 1913. Un mémoire a été consacré à ce personnage atypique à l'École des beaux-arts de Paris ${ }^{17}$ et de nombreuses photographies sont conservées dans les collections publiques à la Bibliothèque historique de la ville de Paris, au musée des Arts décoratifs, à la Médiathèque de l'architecture et du patrimoine... Elles retracent ses différents voyages en Europe et en France, montrent Paris, ses monuments, ses rues et ses musées, l'Exposition universelle de 1900 et la crue de la Seine de 1910.

Fig. 9

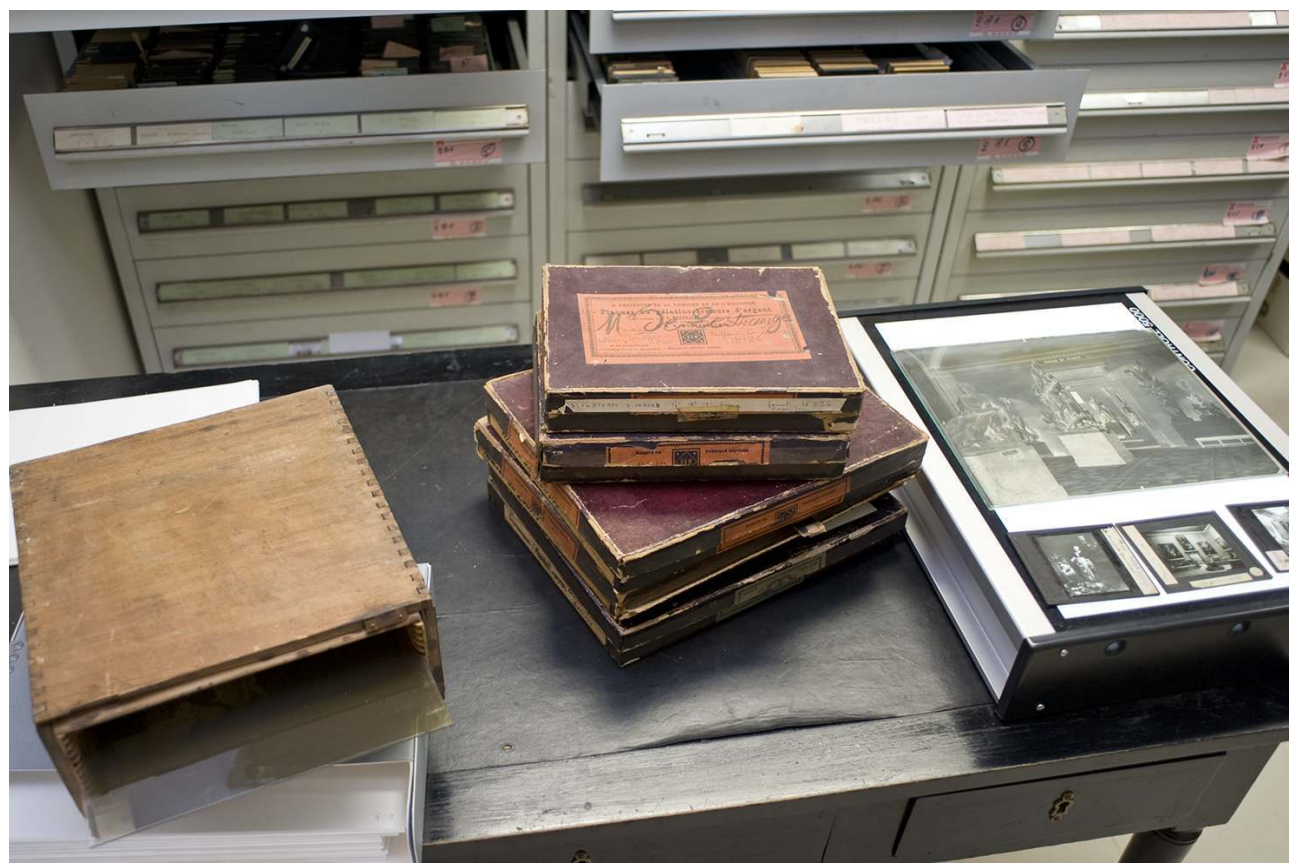

Collection Henry de Lestrange : boîte commerciale, négatifs sur verre grand format, plaques de projection

Arch/EDL 
Fig. 10

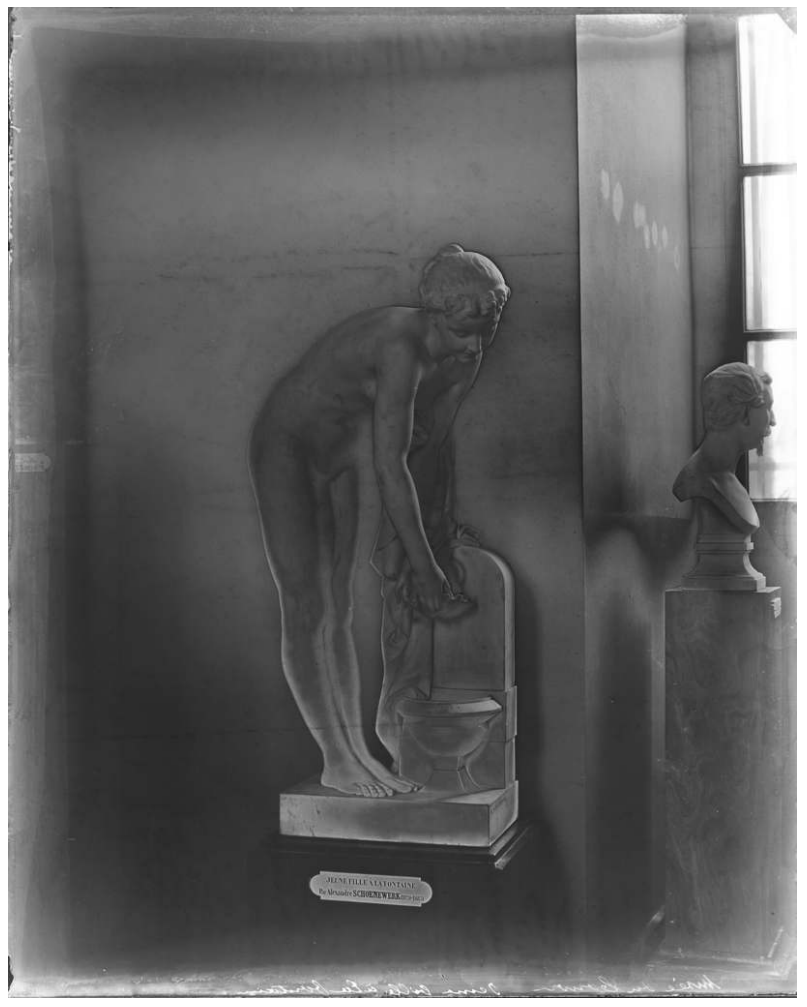

Collection Lestrange : négatif sur verre représentant la Jeune fille à la fontaine d'Alexandre Schoenewerk (1820-1885), Paris, musée du Louvre, PH000036345.

Arch/EDL 
Fig. 11

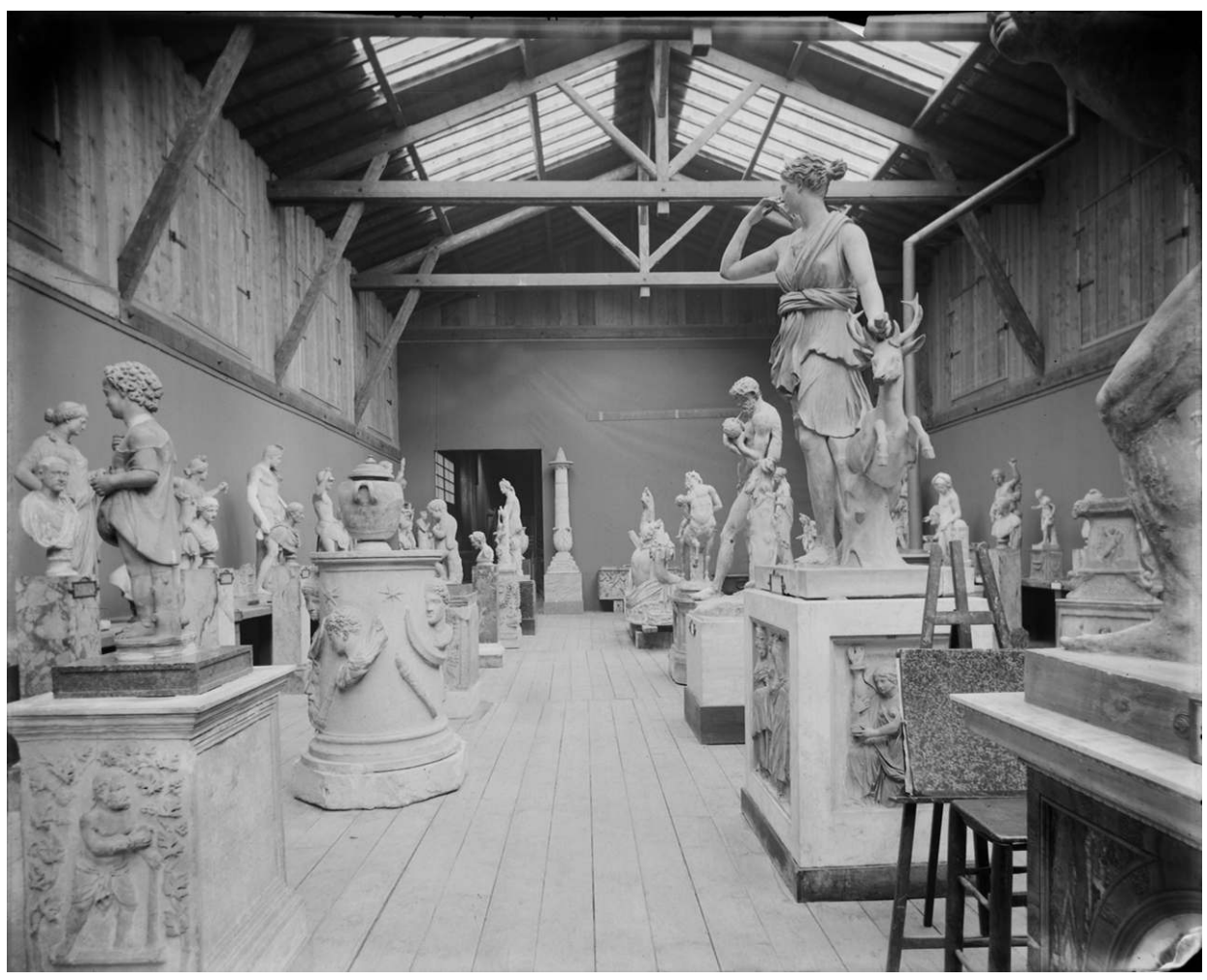

Collection Lestrange : une gypsothèque, positif d'après un négatif sur verre Arch/EDL

\section{Mise en valeur des collections}

6 Le premier état des collections a eu pour conséquence une prise de conscience de l'intérêt pédagogique et patrimonial du fonds, qui se concrétisa par plusieurs actions de prévention, de conservation et d'étude.

\section{Prévention et conservation}

7 En 2012, l'Institut national du patrimoine organisa avec l'École du Louvre un « chantier des collections » à la photothèque sous la direction de Giulia Cuccinella, restauratrice de photographies, enseignante au département des restaurateurs de l'INP, et coordonné par Dominique de Font-Réaulx, chargée du groupe de recherche sur l'Histoire de la photographie à l'École du Louvre. Ainsi, trois stagiaires conservateurs de l'Institut national du patrimoine, trois stagiaires restaurateurs ( $1^{\text {re }}$ année) et trois stagiaires en Master 2 (régisseur) à l'École du Louvre y participèrent ${ }^{18}$. Le premier objectif fut de mettre en place une chaîne opératoire d'analyse des objets: identification, documentation (photographie, récolement...), constat d'état, dépoussiérage jusqu'au reconditionnement, à l'emballage et à la relocalisation. Le second fut «d'appréhender la complémentarité des différentes professions et de réaliser un travail de coopération autour d'un objectif commun et dans un temps limité ». Le rapport rédigé par les stagiaires rend compte de la tâche réalisée et de l'état physique des collections au premier inventaire détaillé de certains ensembles 
photographiques depuis leur transfert dans l'aile de Flore ${ }^{19}$. Le détail du contenu d'une armoire métallique a sorti de l'oubli des richesses insoupçonnées: un lot composé d'une quarantaine de plaques de projection et de négatifs sous verre figurant des vues des « concours » du musée du Luxembourg (lundi 13 novembre 1899, 1905) et du Louvre des années 1901 à 1905, photographiées par Henry de Lestrange, donne des repères chronologiques pour dater les plaques grand format déjà mentionnées (fig. 12). Une vingtaine de vues stéréoscopiques, reproduisant une perception du relief à partir de deux images planes, illustrent des sites grecs, l'Acropole d'Athènes, Delphes, le Cap Sounion $^{20}$ (fig. 13). Isolé, un aristotype à la gélatine, également dénommé papier au gélatino-chlorure d'argent à noircissement direct ou papier citrate, offre une très bonne définition. Des négatifs sur verre $18 \times 24$ ont servi au tirage d'une affiche dont un exemplaire est conservé au département des Estampes à la BnF. Elle annonce la conférence de René Geoffroy en février 1954 sur le trésor de Vix, au bénéfice des écoles grecques sinistrées par le séisme de 1953, à l'initiative de l'association de l'École (fig. 14). À ces documents dont la provenance est parfois inconnue, s'ajoutaient 120 autochromes, «diapositives » en couleurs sur plaques de verre représentant des œuvres de primitifs et de peinture française $\mathrm{xvIII}^{\mathrm{e}}$ siècle, rangés dans les tiroirs des meubles métalliques. Leur technique spécifique ${ }^{21}$ restitue les couleurs de l'original photographié. Leur production et leur commercialisation furent brèves, précisant ainsi leur date d'acquisition entre 1905 et 1930 (fig. 15).

Fig. 12

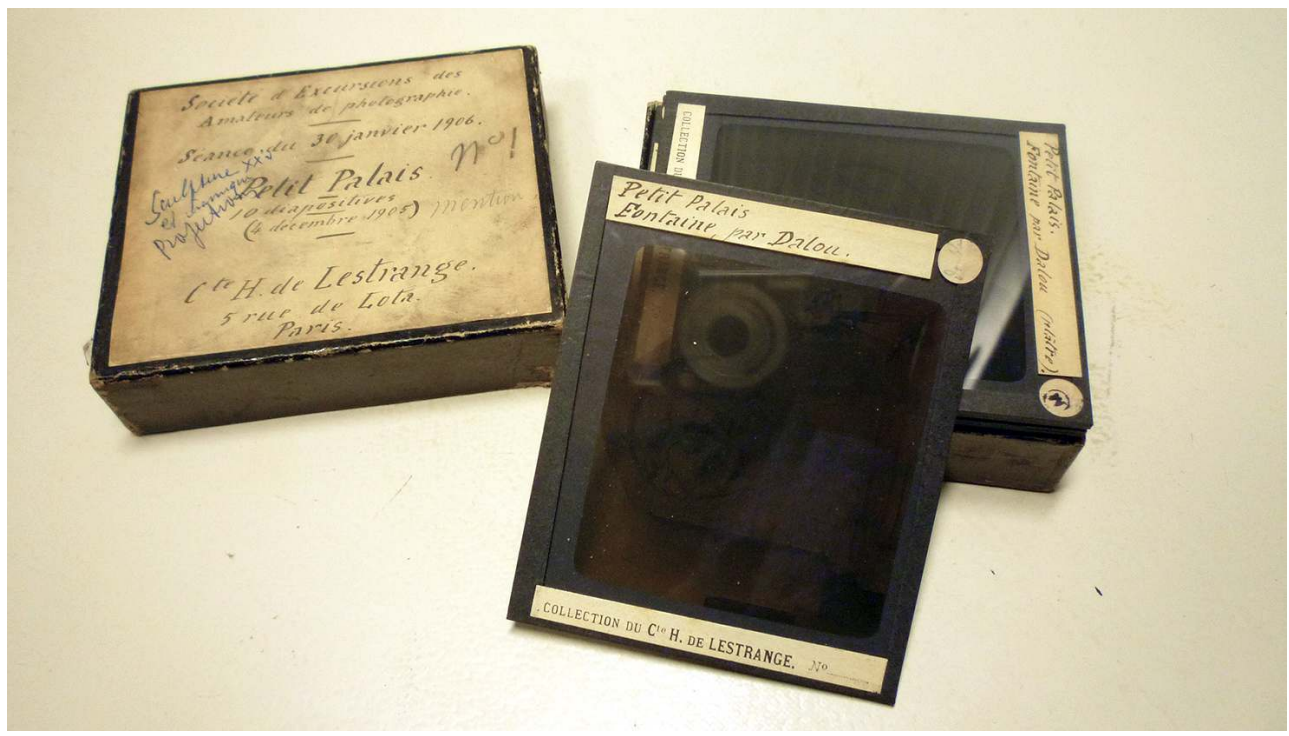

Collection Lestrange : boîte contenant les négatifs d'une séance au Petit Palais en date du 4 décembre 1905, Société d'excursion des amateurs de photographie, séance du 30 janvier 1906

ARCH/EDL 
Fig. 13
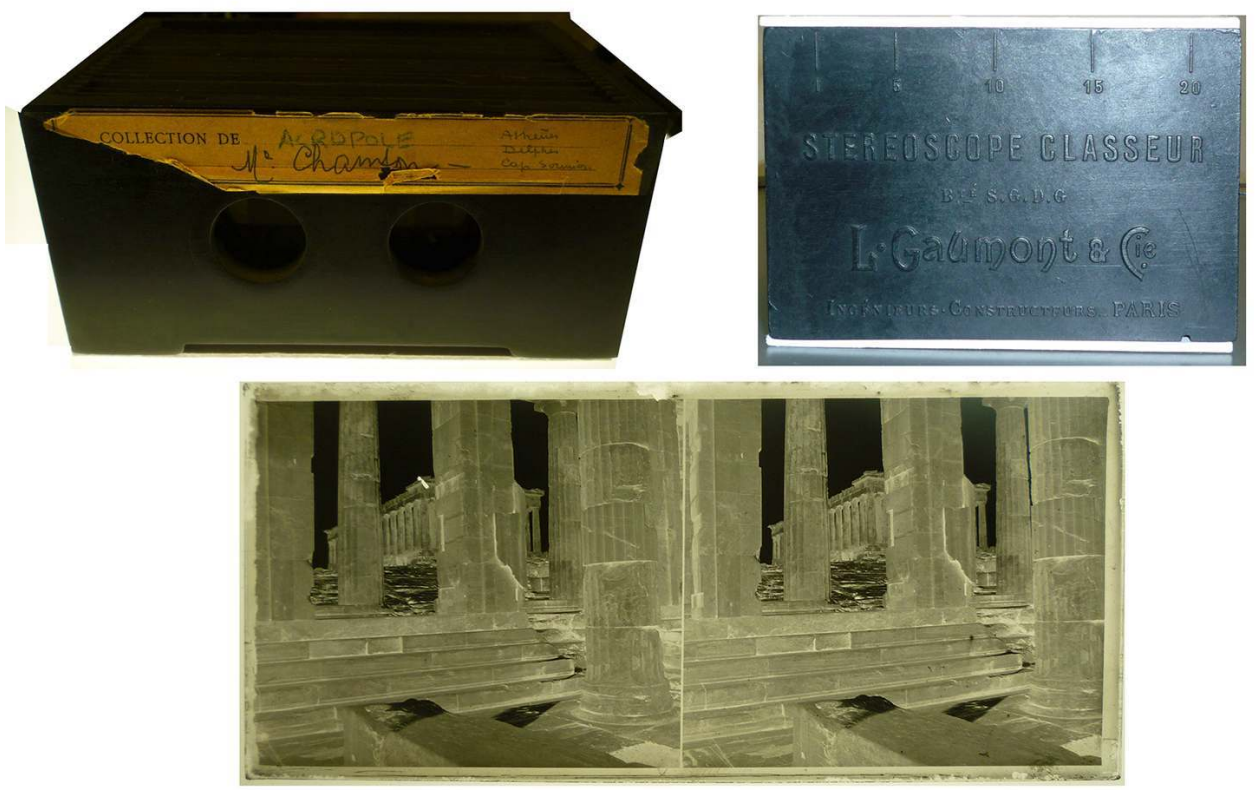

Classeur stéréoscope et vue stéreoscopique de l'Acropole (Delphes, Cap Sounion), collection de M. Chambon

\section{ARCH/EDL}

Fig. 14

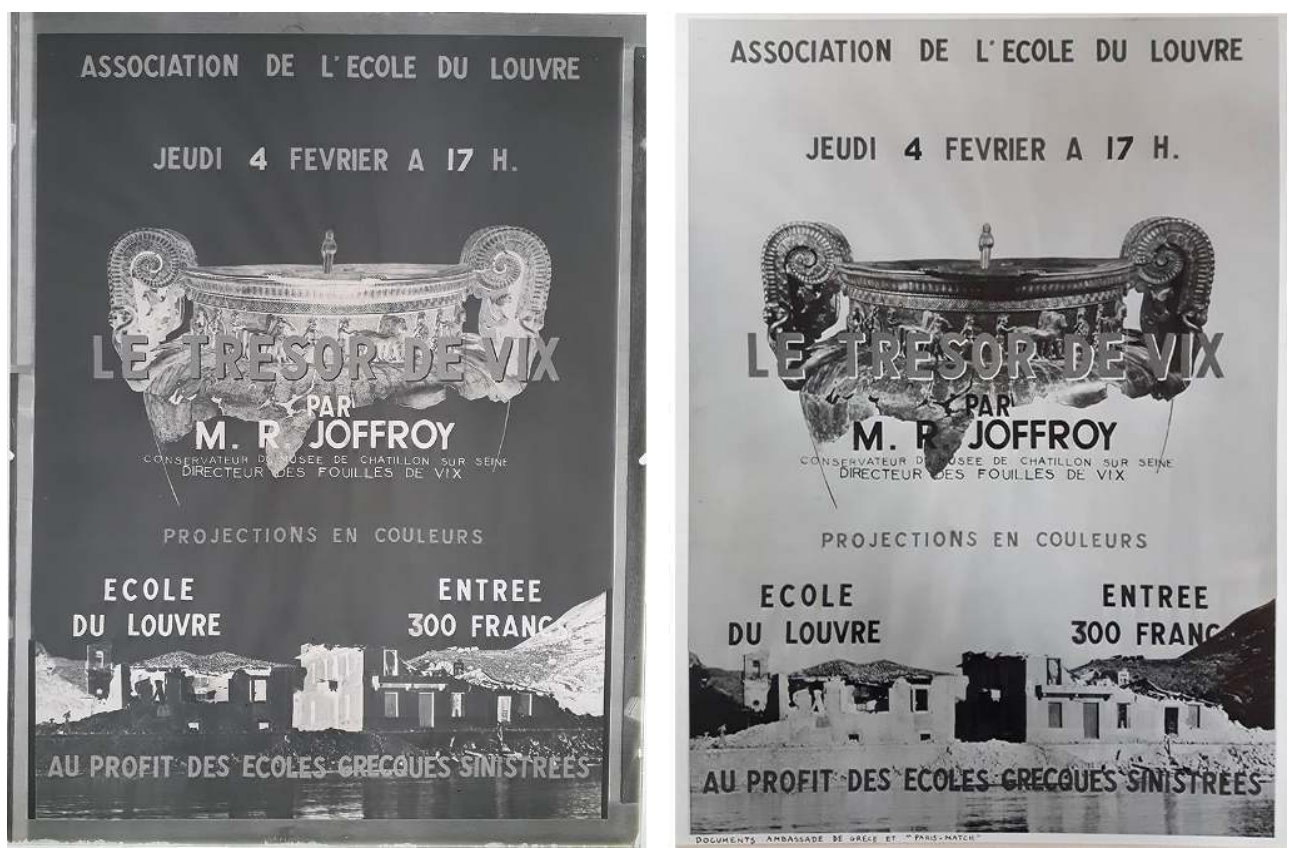

Négatif sur verre de l'affiche annonçant la conférence de René Geoffroy en février 1954 sur le trésor de Vix, au bénéfice des écoles grecques sinistrées par le séisme de 1953 (gauche) ; affiche, Paris, Bibliothèque nationale de France, département des Estampes, recueil VA 218 E, microfilm A16957 (droite)

\section{ARCH/EDL ET BNF}


Fig. 15

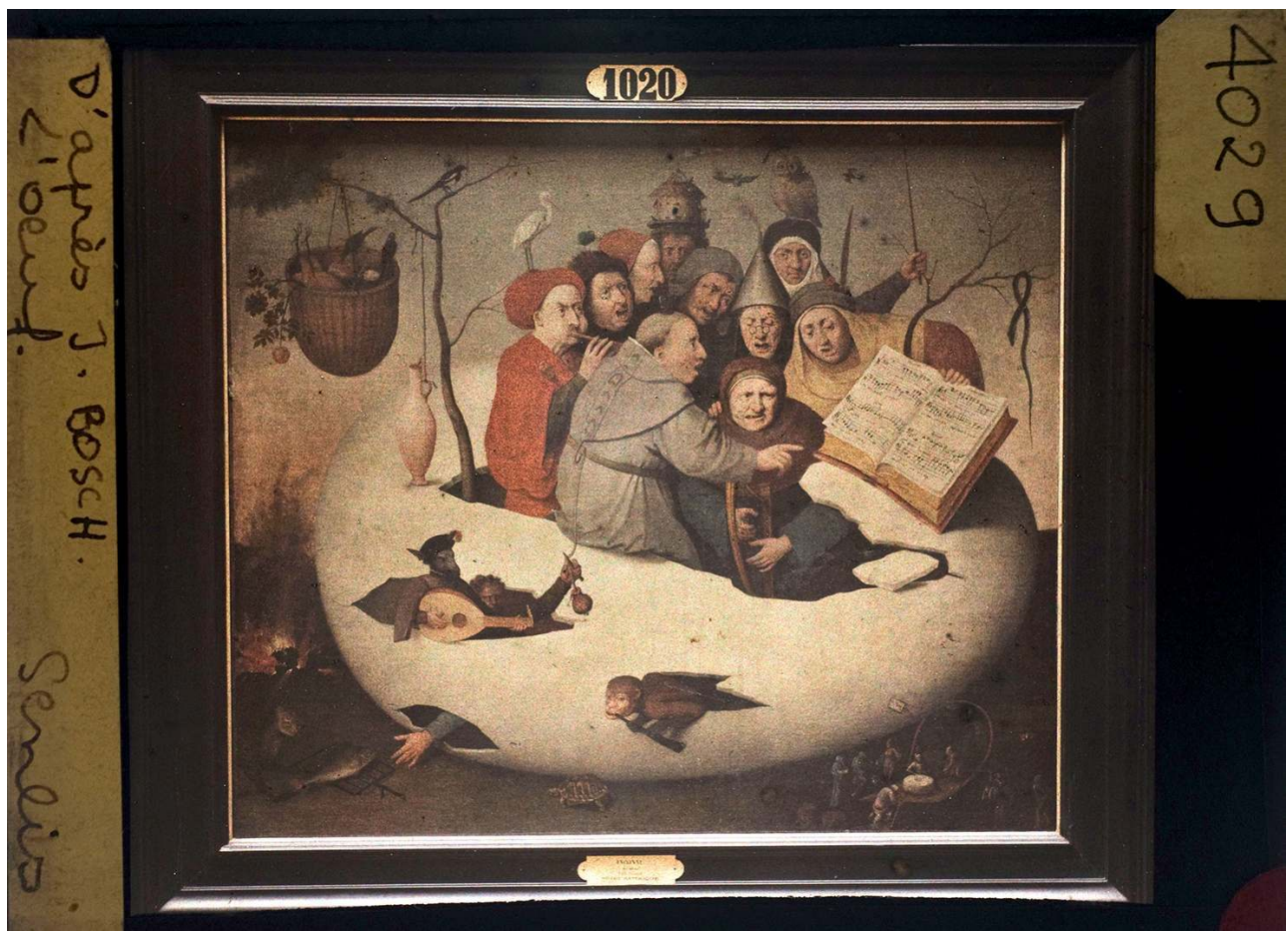

Anonyme, d'après Bosch, L'œuf, musée de Senlis, autochrome, plaque 4029

Arch/EDL

\section{Restauration des plaques}

Dès lors, des mesures de conservation préventive furent prises par la direction de l'École. La collection du comte Henry de Lestrange fut restaurée. Les 155 négatifs sur plaque de verre contenus dans d'anciennes boîtes commerciales portant des mentions manuscrites furent traités ${ }^{22}$ : époussetés, dépoussiérés, nettoyés, consolidés, doublés lorsque les verres étaient cassés ou les émulsions soulevées. Ces clichés ainsi que les plaques $8 \frac{1}{2} \times 10$ d'archéologie grecque, étrusque et romaine furent conditionnés dans des pochettes à rabats en papier de Chronos.

\section{Sujet de mémoire}

Prévention, conservation, restauration furent accompagnées de propositions de stages et de mémoires aux élèves de premier cycle suivant les cours d'Histoire de la photographie, et de deuxième cycle participant au groupe de recherche Histoire de la photographie ${ }^{23}$. À partir d'un corpus patrimonial, de nombreux sujets d'étude pouvaient être traités et peuvent l'être à l'avenir : de l'historiographie (constitution des fonds...) aux techniques de la photographie, de l'utilisation de ces supports dans l'enseignement de l'histoire de l'art à l'histoire du goût... Ainsi, en 2013, Stella Melbye soutint un mémoire de Master 1 intitulé « La reproduction photographique : un outil et un argument dans l'histoire de l'art. L'analyse du don de plaques de projection de Marcel Aubert (1884-1962) situé dans la photothèque de l'École du Louvre ${ }^{24}$ ", sous la direction de Dominique de Font-Réaulx. Ce fonds comprenait environ 2040 plaques, principalement d'architecture et de sculpture du Moyen Âge et de la Renaissance, 
collectionnées par l'historien de l'art au cours de sa carrière. L'objectif fut d'examiner et d'analyser l'ensemble des plaques de projection sous leurs différents aspects, ainsi que de préciser leur rôle en s'appuyant, d'une part, sur la matérialité de l'objet photographique et le phénomène de reproduction des œuvres, et d'autre part, sur l'utilisation scientifique et pédagogique de la photographie, mise en perspective avec les archives des cours de Marcel Aubert déposées à l'Institut national d'histoire de l'art (Fonds 002) et à la bibliothèque centrale des Musées nationaux (MS 319).

\section{Numérisation des plaques}

10 En 2012 commença la numérisation des plaques de verre par les photographes attachés à la photothèque des fonds Marcel Aubert $(2040)^{25}$, Henry de Lestrange (75), d'archéologie grecque, étrusque et romaine $(4056)^{26}$, de peinture et gravure (cours Gaston Brière - 888), de muséographie (cours Germain Bazin - 627 -, dons Gaston Brière - 388 - et Inspection des musées de France -112)27. Plus de 10600 plaques ont été numérisées et 663 sont consultables sur la base Pléiades. Par la dématérialisation, ce vaste chantier eut pour objectif d'assurer une meilleure sauvegarde des supports en évitant les manipulations et en les rendant accessibles visuellement aux chercheurs, aux étudiants et, à terme, à un large public.

\section{Enseignement et plaques de verre}

\section{D'un service des projections à la création d'une clichothèque}

11 La documentation fut un temps à la charge des professeurs. André Michel, conservateur au département des Sculptures qui occupa la chaire d'Histoire de la sculpture de 1898 à 1920, avoua en 1912, dans un plaidoyer en faveur de l'École, " qu'une grande part de son traitement était absorbée par les dépenses qu'entraînait la documentation de ses cours, en particulier par l'achat de ses projections pour les démonstrations au tableau ${ }^{28}$ ». Il en fut de même de Gaston Brière qui, en 1914, déplora l'absence de matériel d'enseignement... Certains dispensaient une grande partie de leurs leçons dans les salles et les galeries épigraphiques du musée du Louvre par des conférences pratiques ${ }^{29}$. Quant à Louis Courajod, adepte d'un enseignement « en face des monuments ${ }^{30}$ ", il constitua une importante collection de moulages pour étendre ses démonstrations et son champ d'étude aux œuvres les plus significatives conservées hors du Louvre. Le moulage tint une place de premier plan dans l'enseignement de la sculpture, même s'il ne pouvait remplacer l'original car il ne rendait ni le toucher du matériau, ni la polychromie. Certes, les premiers professeurs apportaient leur documentation, dessins, gravures, plans, photographies, ouvrages ${ }^{31}$, mais l'École du Louvre se souciait du matériel pédagogique indispensable au déroulement des cours. L'un des premiers exemples coûteux fut lié aux méthodes d'enseignement d'Alexandre Bertrand qui fit exécuter pour le musée des Antiquités nationales nouvellement créé à Saint-Germain-en-Laye des moulages, déposés à l'École pour la formation des futurs conservateurs à la conservation et la présentation des œuvres. Un règlement de 551 francs en paiement de moulages dut être versé à Abel Maître, chef mouleur à SaintGermain, et la direction de l'École du Louvre lui signifia qu'elle n'assumerait plus de telles dépenses ${ }^{32}$. 


\section{Équipement de projection} l'affluence de publics passionnés. Dès lors, l'usage d'un nouvel outil pédagogique s'imposa, les projections lumineuses. Elles marquèrent une transformation décisive du matériel pédagogique, le passage de l'étude sur l'œuvre à un nouveau médium destiné à diffuser les connaissances à une large assistance. Les plaques de verre ou clichés devinrent un support pédagogique privilégié, or les témoignages sont nombreux mais aussi lacunaires. Un « service des projections » fut mis en place et équipa la salle de cours, située dans le salon du grand appartement du général Fleury, d'un écran couvrant un des murs (fig. 2), puis des espaces plus vastes en raison de l'aura de l'enseignant. Autant, en 1902-1903, les cours de Salomon Reinach sur l'histoire générale des arts plastiques attirèrent une foule si nombreuse que l'« on dut ouvrir toutes les portes, multiplier les bancs, rétrécir les tables, entasser le public dans quatre pièces contiguës ${ }^{33}$ ", autant, en 1907, à la suite de la pétition des auditeurs, ses cours sur l'histoire de la peinture furent dispensés dans la galerie Denon équipée à cet effet ${ }^{34}$. Louis Courajod, à partir de 1889, faisait passer à la reproduction des liasses de photos, des recueils entiers de gravures, pour obtenir de simples négatifs, « le temps manquant pour avoir mieux ». Il était assisté, en 1892, de «l'opérateur ordinaire de l'École du Louvre, M. Robert», qui faisait passer «de nombreuses projections photographiques exécutées quelques-unes par M. Durand, l'artiste qui accompagne souvent M. Courajod ${ }^{35}$ ». L'appareil de projection, nouveauté d'alors, devint indispensable.

Pour asseoir ces méthodes d'enseignement, l'École du Louvre fut assistée dans un premier temps par des entreprises spécialisées en matériel de projection et d'édition de photographie qui, au fait des nouveautés techniques, diffusèrent des clichés. Ainsi, la Bibliothèque photographique fondée par Auguste Giraudon en 1875, renommée pour ses photographies d'œuvres présentées au Louvre, à Versailles et dans les expositions temporaires, d'architecture et d'archéologie, prêta des clichés pour les cours de l'année 1888-1889 ${ }^{36}$, puis la maison Leroy fils mit à la disposition de l'École le matériel, la projection étant assurée par Séraphin-Médéric Mieusement ${ }^{37}$, anciennement attaché à la commission des Monuments historiques, enfin l'atelier de reproduction artistique Eugène Gossin prit la relève jusqu'en $1913^{38}$. Quant à Edmond Pottier, il emprunta également des clichés à l'université de Bordeaux (Musée archéologique de l'université de Bordeaux), où une collection, devenue itinérante, avait été constituée dès 1892 par Pierre Paris, éminent archéologue hispaniste ${ }^{39}$.

Dans un deuxième temps, l'École, en contact avec les principaux constructeurs de matériel cinématographique professionnel français, s'équipa d'appareils de projections fixes puis cinématographiques et de tous les accessoires indispensables, dont les différents systèmes d'éclairage existant à l'époque.

En 1913, la maison Radiguet vendit le matériel de projection et les fournitures ${ }^{40}$. Les appareils furent entretenus ${ }^{41}$, modifiés ${ }^{42}$ et renouvelés au fur et à mesure des progrès techniques. En 1922, le procédé de projection Dussaud fut adopté, l'épidiascope, appareil utilisé pour la projection par réflexion d'images sur supports opaques ou la projection par transparence ${ }^{43}$. Il fut complété en 1925 par un appareil de la maison Massiot (fig. 16) pour projections épiscopiques qui reproduisait des vues fixes par transparence ${ }^{44}$. En 1938, un petit appareil de projection de la maison Massiot fut acheté 
${ }^{45}$ et un équipement cinématographique acquis auprès des établissements Debrie, pour remplacer le matériel existant ou équiper les nouvelles salles de cours créées en $1933^{46}$ (fig. 17).

Fig. 16

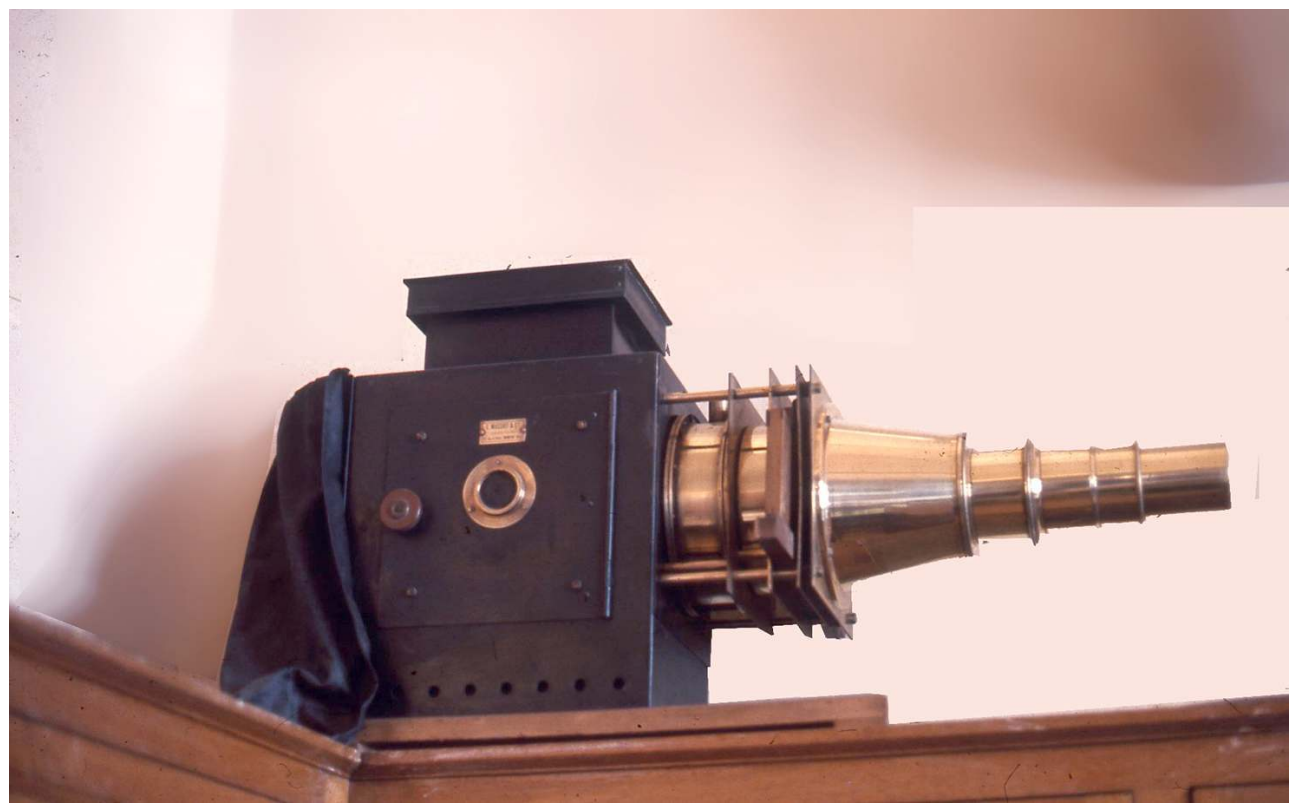

Appareil de projection Massiot Arch/EDL

Fig. 17

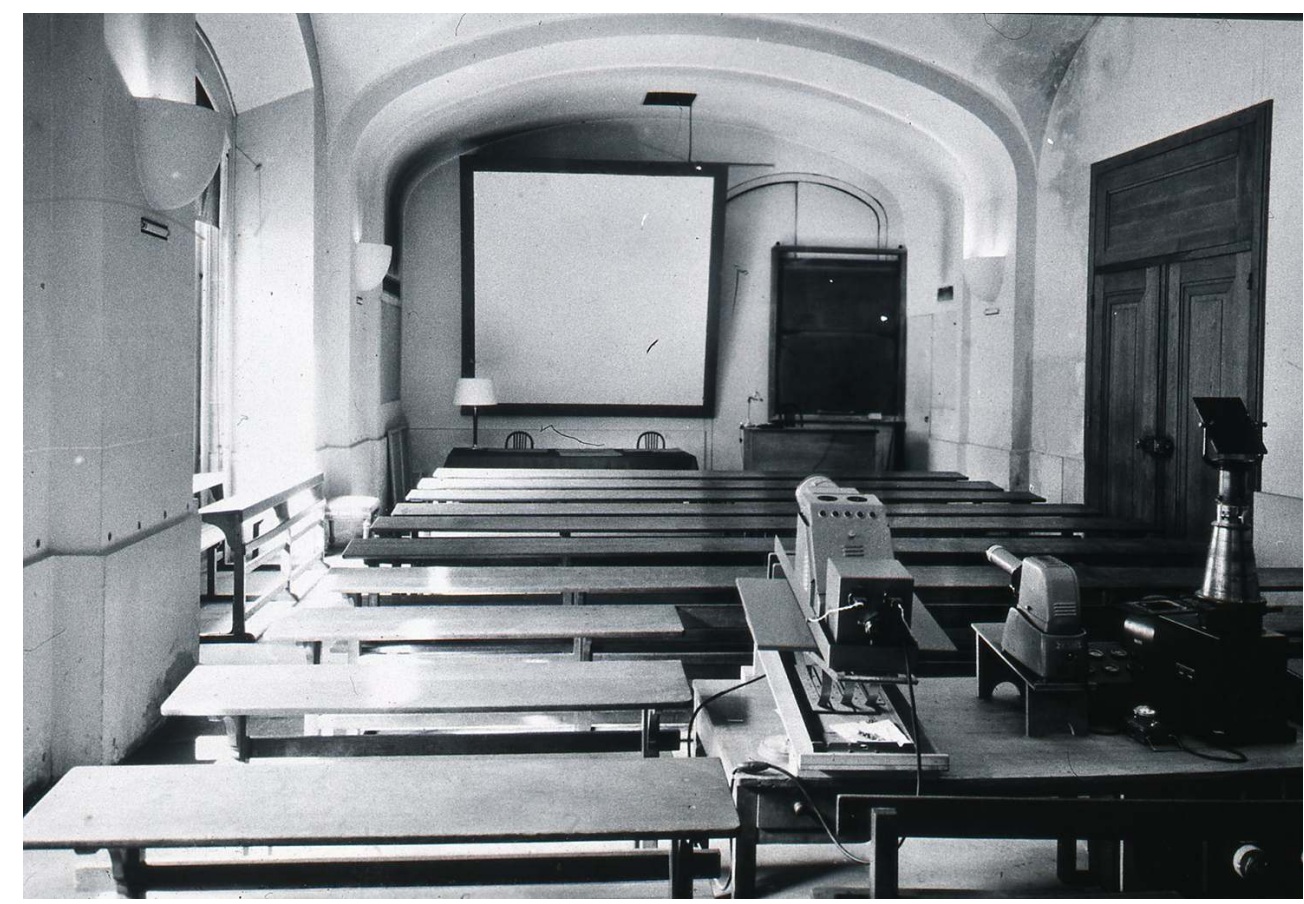

Salle Pottier équipée d'appareils de projection de plaques de verre, de diapositives et épiscope Arch/EDL 
Lors de la présentation de son programme d'aménagement du Louvre, Henri Verne s'enorgueillit de la modernité de l'École du Louvre à la hauteur de la renommée du musée :

Et partout règnent cette clarté et cette netteté modernes, si propices à l'attention tranquille de l'esprit, partout aussi le perfectionnement des appareils. La projection lumineuse des clichés photographiques, des films ou des documents, les hauts parleurs qui amplifient les voix, les murs revêtus de liège qui les amortissent, le grand éclairage diffus ou le petit éclairage tombant de plafonniers minuscules et invisibles, le sol silencieux, l'entrée directe et commode par la porte et la cour Visconti, la communication avec le Musée qui se fera tantôt familière, tantôt solennelle par la prolongation de l'escalier Daru, tout concorde pour rendre matériellement aisé et efficace le travail de nos mille cinq cents élèves ou auditeurs ${ }^{47}$.

Devis et factures traduisent le coût de l'entretien d'un matériel onéreux par l'établissement Mollier et l'achat, en 1956, d'un appareil de projection pour clichés de petit format, estimé à 100000 francs et répondant aux évolutions techniques et à la conquête des diapositives ${ }^{48}$.

Quatre projecteurs sont conservés dans la salle d'archives de l'École ainsi qu'un "tableau de bord ", permettant de coordonner la projection des différents supports de cours - plaques de verre, livres, photographies et diapositives (fig. 18), et deux épidiascopes Ernst Leitz gmbh Wetzlar à focus Leica qui furent utilisés jusque dans les années 1980.

Fig. 18

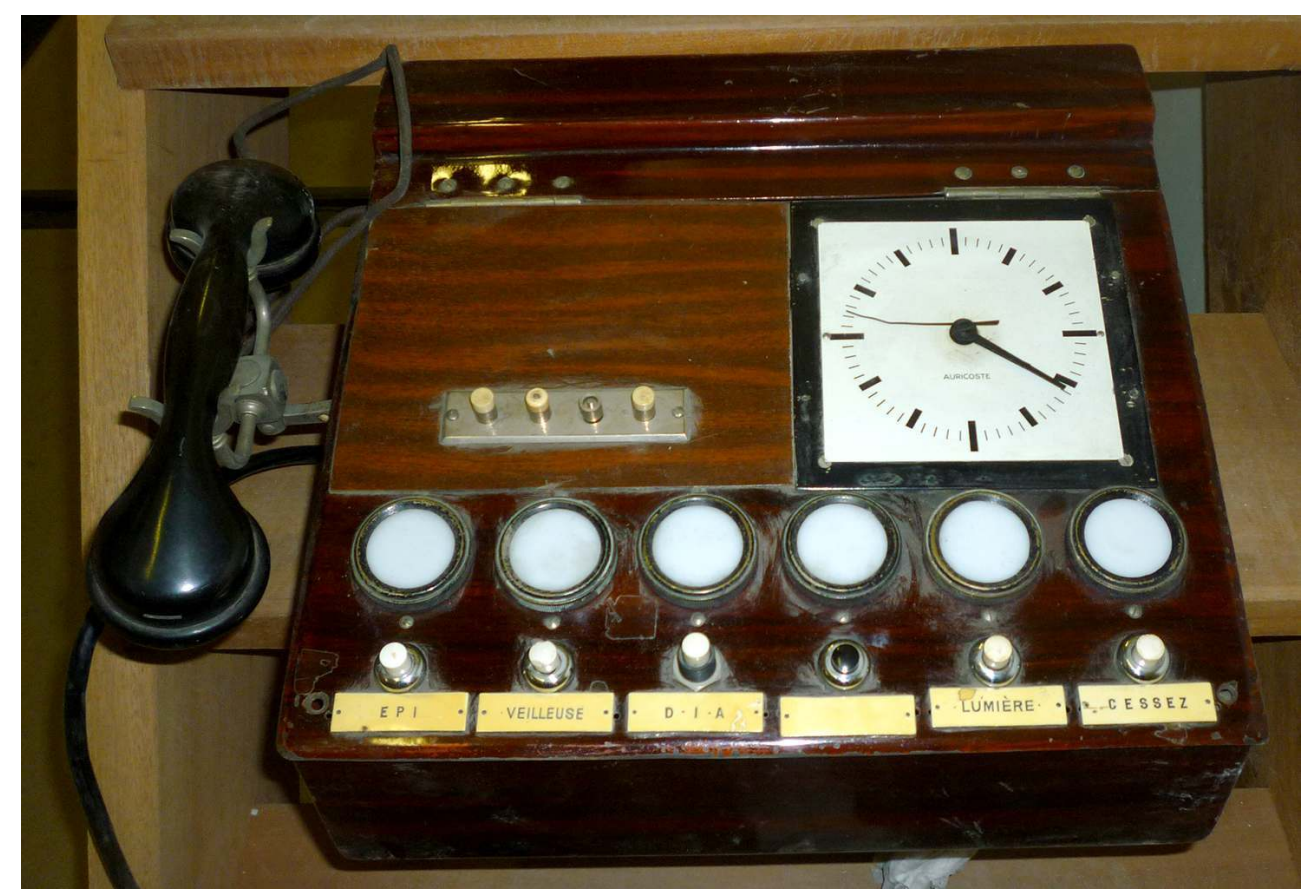

«Tableau de bord » permettant de coordonner les différents types de média projetés par les enseignants

Arch/EDL 


\section{Acquisition des médias}

16 matériel performant adapté aux nouvelles salles de cours ${ }^{49}$, un fonds d'images fut constitué avant l'existence d'un local dédié à la photothèque, soit par dons, soit par achats auprès de particuliers ou de maisons d'édition, soit par un photographe affecté au musée. La documentation photographique, riche d'environ 2000 clichés en 1934, en possédait plus de 7000 en 1938, dont un nombre important de la collection Rothschild. Ces clichés devaient répondre à l'enseignement d'André Blum, titulaire de la chaire de gravures et premier conservateur chargé d'organiser le fonds Rothschild au cabinet des Estampes du musée du Louvre ${ }^{50}$.

\section{Dons, dépôt et achats}

1903, Félix Martin-Sabon, fervent auditeur de Louis Courajod puis d'André Michel, offrit 100 clichés à projection pour illustrer les leçons des professeurs d'Histoire de la sculpture $^{51}$ et proposa même de photographier les œuvres présentées dans les salles de la Renaissance et des Temps modernes pour les cours à venir. Puis, en 1928, Salomon Reinach déposa les positifs qui lui avaient servi pour ses cours d'histoire générale des arts plastiques (1902-1903) et d'histoire de la peinture (1905-1910)52. Un fascicule manuscrit intitulé "Catalogue des positifs pour projections, Fonds Salomon Reinach " (fig. 19) correspond probablement aux plaques déposées (soit 2935 clichés, conditionnés dans des boîtes numérotées de 1 à 307) ${ }^{53}$.

Fig. 19

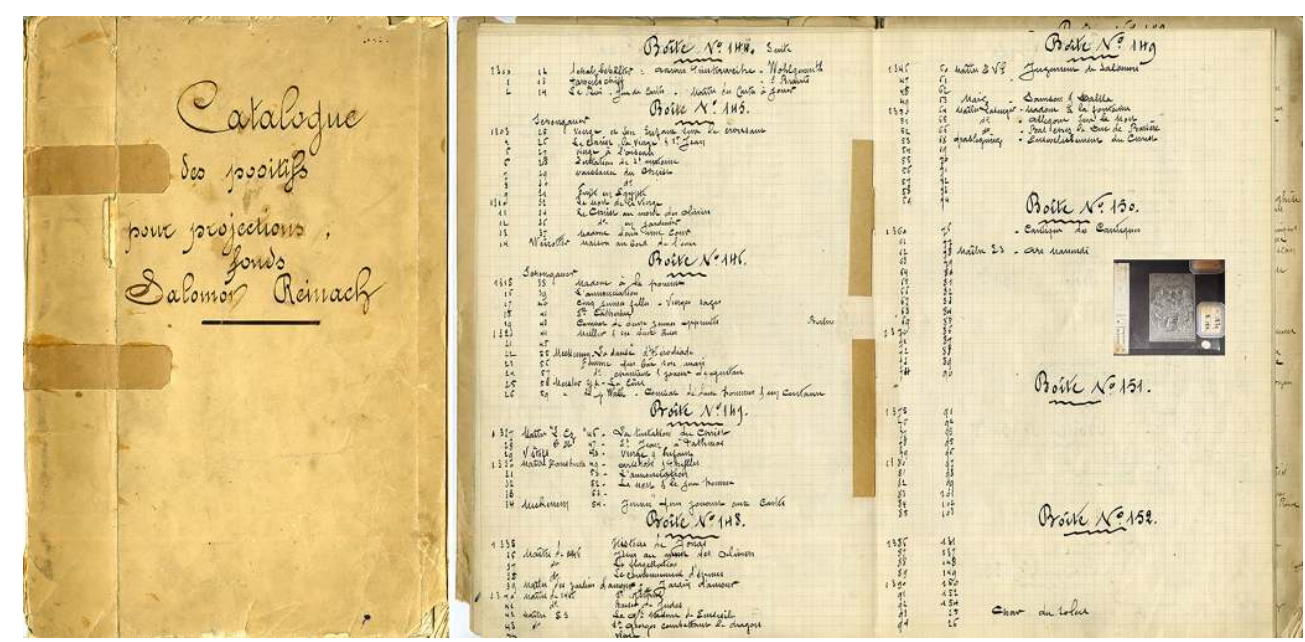

Catalogue des positifs pour projections, fonds Salomon Reinach, inventaire n 1370 et plaque de projection, maître ES

Arch/EDL

D'autres dons datent des années 1960. Celui de Gaston Brière en avril 1967, conservateur du musée de Versailles, qui enseigna l'histoire de la peinture de 1912 à 1924, puis l'histoire des collections et des musées d'art moderne de 1927 à 1938 (soit 2000 plaques de projection sur l'histoire des collections et des musées, la peinture espagnole, hollandaise et flamande). Le fonds Marcel Aubert, qui enseigna la sculpture de 1939 à 1949, légué par son épouse, contient 2040 plaques de projection 
d'architecture et de sculpture du Moyen Âge et de la Renaissance. Un don de l'Inspection des musées de France est constitué de clichés de muséologie (140). Dans ce lot se trouvaient des plaques commandées par Jean Vergnet-Ruiz, notamment le cloître Saint-Jean d'Angers, les musées d'Arles... (fig. 20). Certains dispersés dans les tiroirs restent à explorer: celui de Raymond Regamey, historien de l'art attaché au département des Peintures (1926) avant d'entrer au noviciat (1928) - architecture, sculpture religieuses - ; Hubert ; Arasse ; Michel Leroy...

Fig. 20

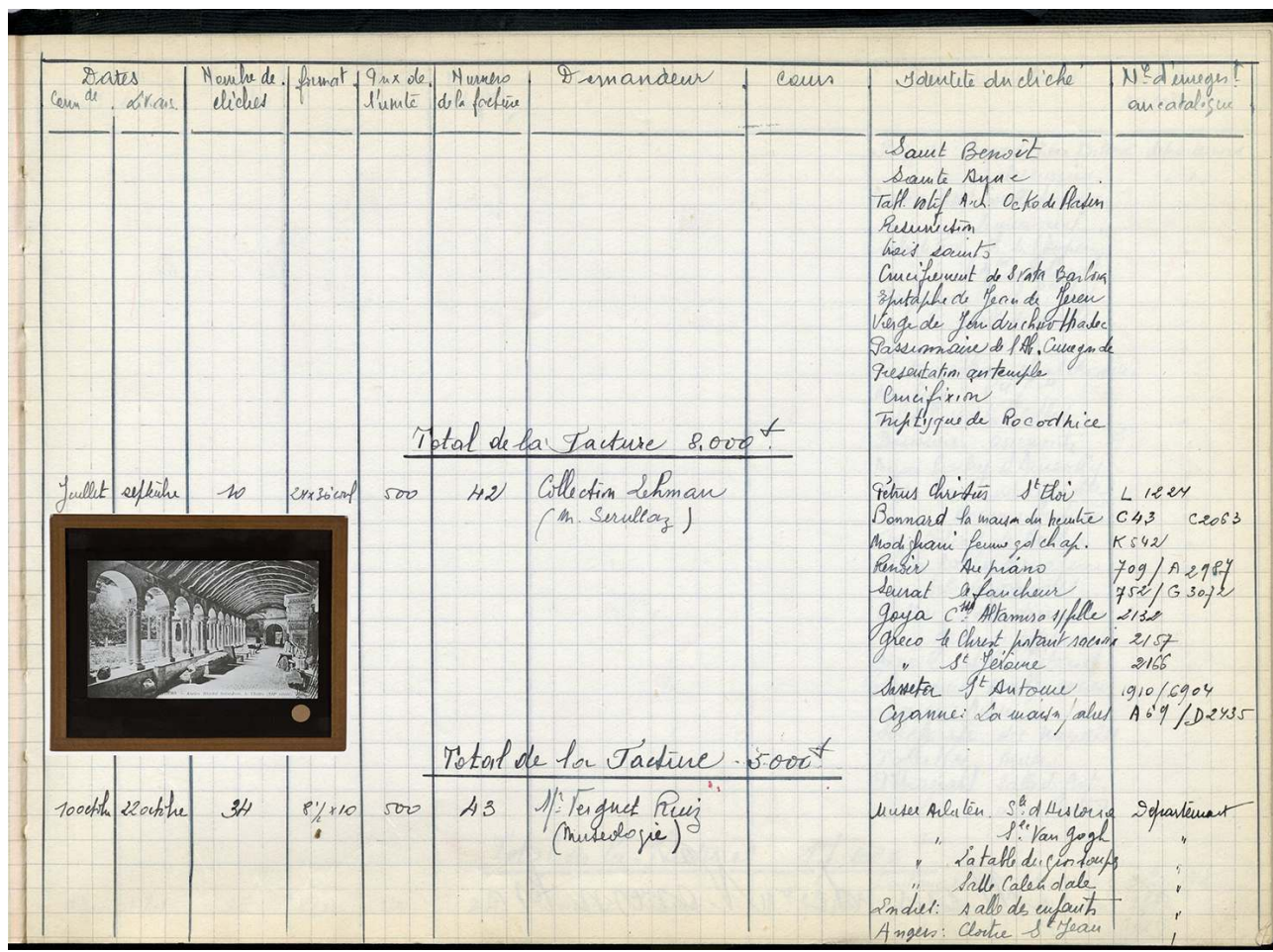

Registre 1957, 22 octobre : commande de Jean Vergnet-Ruiz pour son cours de muséologie. Plaque du cloître Saint-Jean (don de l'Inspection des musées de France)

Arch/EDL

En ce qui concerne les dons de Jean Capart (1933), conservateur des Musées royaux de Belgique, d'une collection d'images d'art en vue de servir à leur diffusion en France ${ }^{54}$, et de Perry Cott (1960), conservateur à la National Gallery de Washington, de 500 clichés en couleurs de peintures anciennes ${ }^{55}$, rien n'assure qu'ils furent constitués de plaques de verre.

\section{Commandes}

Le fonds de plaques de verre fut enrichi par des commandes de clichés qu'illustrent des courriers, accompagnés de listes précises établies par les enseignants, et des factures ${ }^{56}$.

Les clichés furent commandés aux maisons d'édition photographique spécialisées françaises et étrangères dont les noms sont pérennisés grâce aux étiquettes collées sur les plaques de verre : Archives Photographiques, 1 bis rue de Valois, Paris ; J. E. Bulloz Éditions photographiques, 21 rue Bonaparte, Paris; Giraudon; Maison de la Bonne Presse, 5 rue Bayard, Paris; Maison AD Braun; Braun Clément et $C^{\text {ie }}$; Radiguet et Massiot ; projection Moltoni, 16 rue du Calvaire, Paris ; Paul Robert éditeur ${ }^{57}$... En 1913, 
une note de l'établissement Gossin résume les sommes dues pour les projections lumineuses et précise le nom des professeurs et le nombre de cours, parmi lesquels André Michel qui assura l'illustration de 22 cours sur les 25 qu'il fit ${ }^{58}$. En 1934, les leçons d'histoire générale de Pierre-Edmond Ladoué, conservateur adjoint du musée national du Luxembourg (1930-1938), furent constituées à partir des clichés de l'École et des Archives photographiques (fig. 21) ${ }^{59}$. En 1939, une liste de clichés fut adressée à la maison Massiot pour les cours d'histoire générale de l'art de Charles MauricheauBeaupré, conservateur au musée de Versailles ${ }^{60}$.

Fig. 21

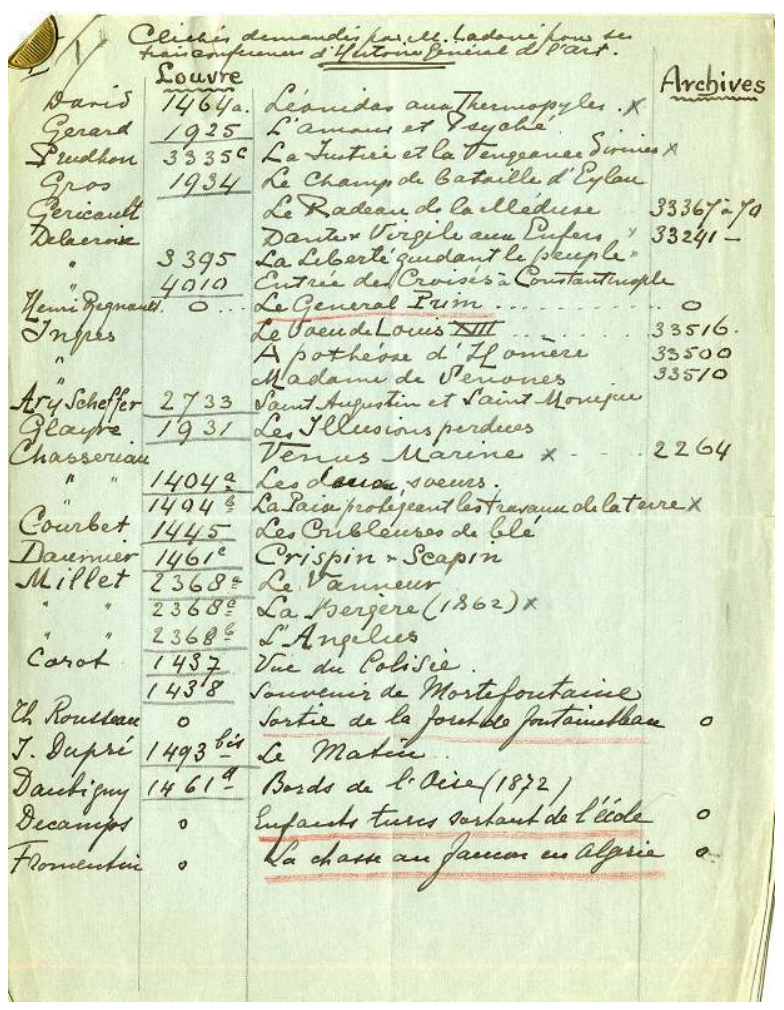

Liste de clichés commandés par M. Ladoué pour ses conférences d'Histoire générale de l'art (23 avril 1934)

Arch/EDL

À partir de 1937, M. Séarl, chef de l'atelier de photographie, employé par les services commerciaux, fut désigné par Henri Verne pour exécuter les commandes des enseignants. Il fut rémunéré à la tâche sur un budget dédié à l'École du Louvre, comme le laissent apparaitre les courriers échangés entre le directeur des Musées nationaux, le secrétariat général ou la responsable de la clichothèque et les enseignants ${ }^{61}$. Il interrompit brièvement son activité en 1938, fut remplacé par $\mathrm{M}^{\mathrm{me}}$ Zuber, chargée de mission à la bibliothèque de l'École du Louvre et photographe ${ }^{62}$, puis reprit son travail au sein du Louvre. La dernière facture date du 19 novembre 1957. Il fut chargé en grande partie de reproduction d'après des ouvrages, ainsi que des photographies d'objet dans les salles ${ }^{63}$. Jean Chuzeville prit la relève à partir de 1958. 


\section{Achats aux particuliers}

21 Quelques achats ont fait l'objet d'un travail documentaire, d'une enquête tarifaire et de négociations.

En 1944, $\mathrm{M}^{\text {me }}$ Doumic-Gillet proposa à Jacques Jaujard 1909 clichés ayant servi à son époux, Louis Gillet, historien d'art et historien de la littérature française ${ }^{64} . \mathrm{M}^{\mathrm{me}} \mathrm{Pardo}$, secrétaire adjointe, fut priée d'examiner la collection, en demandant éventuellement conseil aux enseignants, de la classer, d'établir un relevé sommaire par catégories, dans la perspective d'un achat partiel ou total prônant des méthodes intelligentes et réfléchies. Une estimation comparative des prix en vigueur en magasin ${ }^{65}$ et un inventaire exhaustif furent dressés, 1443 clichés furent achetés au prix de 15 francs pièce (soit un coût total de 21645 francs) et 466 furent rendus à sa veuve ${ }^{66}$. La peinture et la gravure étaient particulièrement bien représentées, et parmi ces plaques, 180 œuvres des grands maîtres faisaient double emploi ; 350 concernaient l'architecture antique, française et étrangère, 268 la sculpture française et étrangère. Le deuxième lot proposé par $\mathrm{M}^{\mathrm{me}}$ Doumic-Gillet en 1947 fut refusé faute de crédit ${ }^{67}$.

En 1954, l'École enrichit ses collections de peinture et de sculpture françaises XvIII ${ }^{e}$ et

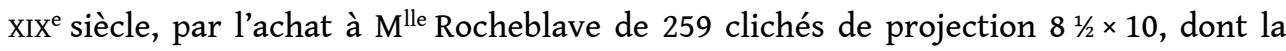
liste est précisément dressée, pour la somme de 3500 francs $^{68}$.

\section{Passage de la plaque de verre aux diapositives}

22 Au début des années 1950, les enseignants utilisèrent des supports différents pour leurs cours. Une facture du service photographique de la Bibliothèque nationale $\left(\mathrm{n}^{\circ} 21760\right)$ en date du 26 avril 1951, adressée par Pierre Pradel à la responsable de la clichothèque, indique la commande aussi bien « d'épreuves sur clichés existants » en format $9 \times 12 \mathrm{ou}$ $13 \times 18$ que des diapositives $24 \times 36$ pour son cours sur la bijouterie. Dès juin 1956, la secrétaire de l'École du Louvre, $\mathrm{M}^{\mathrm{me}}$ Vinès, indiqua clairement la politique d'octroyer une large place aux clichés couleur $(24 \times 36)^{69}$, et malgré le tarif unitaire plus élevé, l'acquisition d'un nouvel appareil de projection s'imposa. Cette décision fut confortée par la proposition du directeur du Centre international de la photographie à $\mathrm{M}^{\mathrm{me}}$ Vinès ${ }^{70}$ de fournir gratuitement ou au prix de revient un nombre important de clichés en couleurs $(24 \times 36)$ pour l'année scolaire 1956-1957. Ces clichés seraient faits d'après les œuvres exposées dans les musées, les monuments et les collections particulières accessibles. Le directeur des musées de France $^{71}$ décida d'affecter cette offre à l'enseignement de l'histoire de la peinture, depuis les cours sur les fresques romanes et gothiques dispensé par Paul Deschamps ${ }^{72}$ jusqu'à la période contemporaine ${ }^{73}$, « du Cubisme à nos jours ", par Bernard Dorival. Deux registres de commandes et de prêts d'images des années 1956-1957 74 et 1958-1960 75 traduisent d'une part la progression de l'usage de la diapositive et le maintien de la plaque de verre, et d'autre part une gestion rigoureuse. Le dernier enseignant à commander des plaques de verre fut Pierre Pradel le 15 décembre 1960.

\section{Collections en 2018}

L'expertise réalisée avec la Mission photographique du ministère de la Culture fut l'occasion d'évaluer les collections de plaques de projection, estimées à 45000 . Les fonds sont classés par domaines thématiques (sculpture, peinture, archéologie) ou 
historiques (dons, cours) et couvrent l'ensemble des champs spécifiques de l'archéologie, de l'histoire de l'art européen et extra-européen et de la muséologie.

\section{Positifs}

Le fonds est constitué dans sa majorité de plaques de projection (clichés) de format $8 \frac{1}{1 / 2} \times 10$ émanant de différents éditeurs publics ou privés déjà évoqués, de photographes attachés au Louvre, d'autres reconnus, Félix Martin-Sabon, Henry de Lestrange... et certains non identifiés, parfois d'enseignants eux-mêmes ${ }^{76}$. Nombre de clichés d'archéologie grecque et romaine sont des vues de photographies publiées dans des ouvrages (fig. 22), les clichés de muséographie sont pour une part des reproductions de cartes postales, parfois conservées à la photothèque (fig. 23). Ces reproductions d'après ouvrages ou cartes postales sont dignes d'intérêt. Elles ont permis de constituer rapidement un fonds documentaire apportant à l'enseignement une plus grande diversité de thèmes et d'objets, incitant aux méthodes comparatives, un nouvel outil pédagogique au service de nouvelles disciplines: l'archéologie, l'histoire de l'art, la muséographie.

Fig. 22

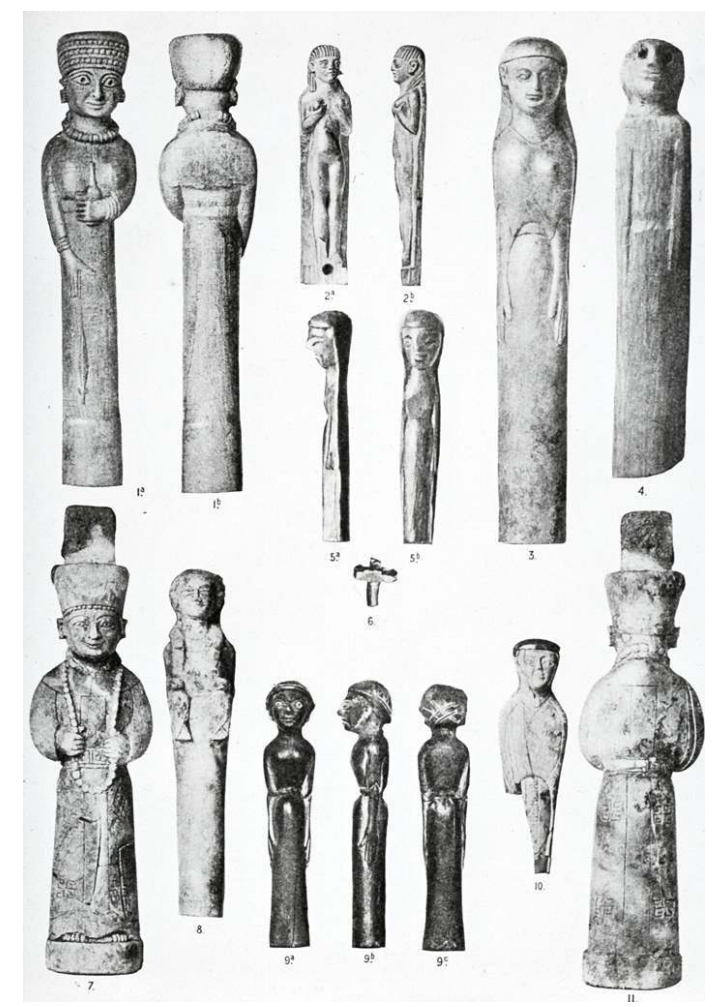

Reproduction d'après un ouvrage : planche de statuettes en ivoire provenant d'Ephèse, fonds EDL/ AGER

Arch/EDL 
Fig. 23
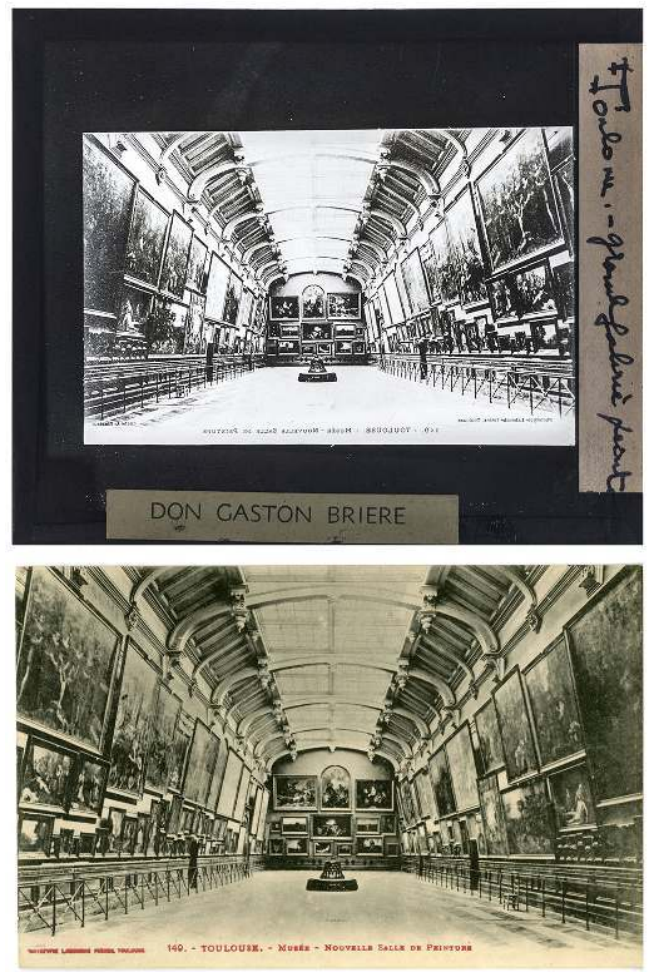

Reproduction d'après une carte postale : Toulouse, musée, nouvelle salle de peinture, plaque de verre, don Gaston Brière ; carte postale Arch/EDL

Les collections sont classées par dons, par spécialités, par domaines ou par peintres. Les dons sont identifiés par des étiquettes collées soit sur les plaques et fiches, comme le don Gaston Brière (fig. 23 et 24), soit sur les fiches pour le fonds Aubert (fig. 25); certains cours sont isolés par des intercalaires disposés dans les tiroirs des meubles métalliques (Rey, Bazin). 
Fig. 24

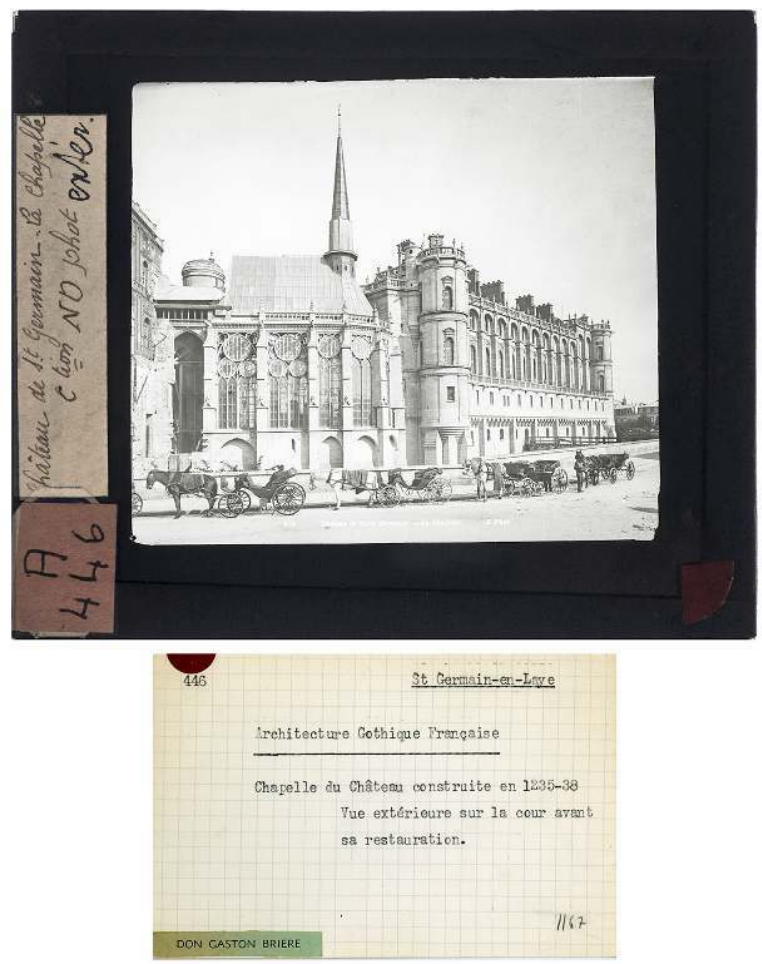

Saint-Germain-en-Laye, chapelle vue extérieure sur la cour avant restauration : fiche et plaque de verre, 446A, don Gaston Brière

Arch/EDL 
Fig. 25

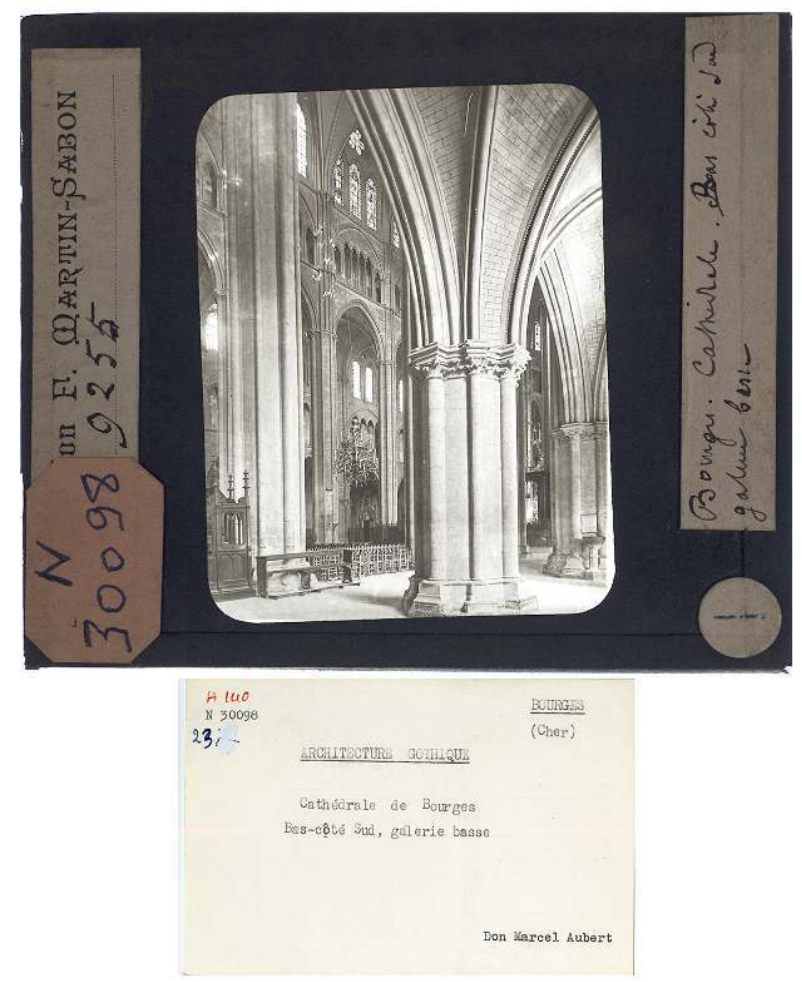

Plaque de verre de la cathédrale de Bourges, collection F. Martin-Sabon, et fiche, don Marcel Aubert N30098

Arch/EDL

Les plaques de verre illustrant le cours de Gaston Brière sont un témoignage de la création de la chaire de muséographie en 1927 avec son cours sur l'histoire des collections et des musées d'art moderne. À partir de 1941, le cours est réorganisé et axé sur l'histoire, les principes généraux, l'organisation et la présentation des œuvres dans les musées français et à l'étranger. Cette nouvelle vision a contribué à l'enrichissement du fonds initial, grâce à Germain Bazin (fig. 26), qui enseigna à l'École du Louvre de 1938 à 1971, et à Jean Vergnet-Ruiz (1956-1960). 
Fig. 26

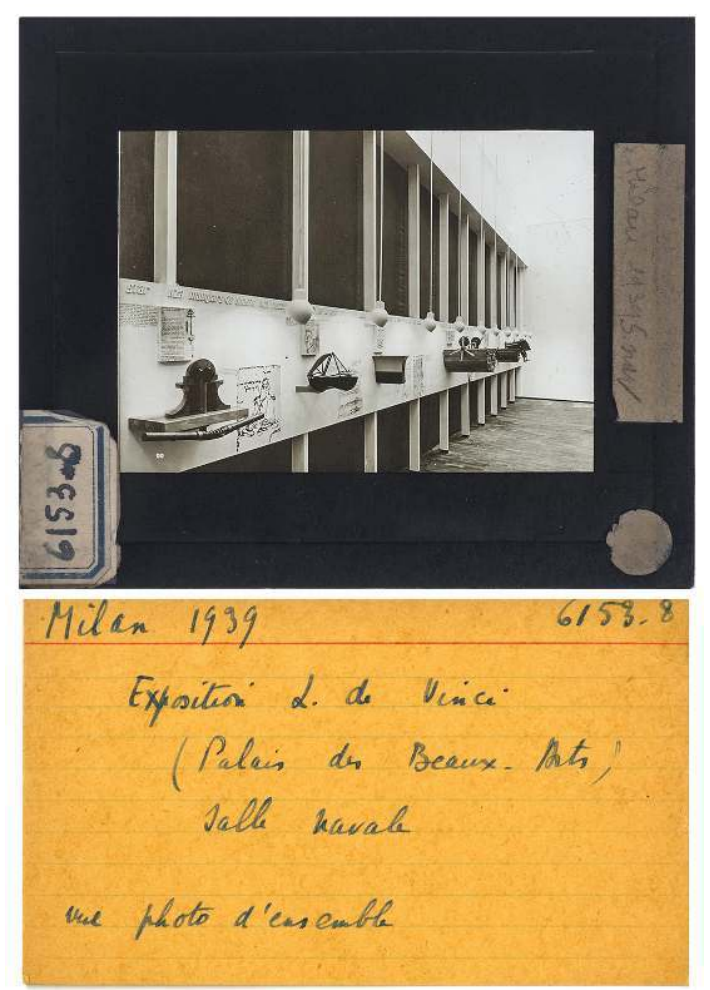

Milan, exposition Léonard de Vinci, 1939, plaque et fiche 61538 : salle des proues, cours Germain Bazin

Arch/EDL

Les 4560 clichés d'archéologie grecque, étrusque et romaine retracent l'enseignement de la céramique dispensé par Alfred Merlin de 1925 à 1927 et par Pierre Devambez de 1938 à 1966, de la sculpture par Étienne Michon de 1910 à 1931 et par Jean Charbonneau de 1931 à 1965, et ceux d'histoire générale de l'art qui furent proposés à $M^{\text {me }}$ MollardBesques, quand elle reprit le cours en 1956 (voir infra).

Les autres ensembles, gravure et enluminure (2 280), peintures française et étrangère (15 000), patrimoine (5 300), sculpture (1 500), objets d'art, mobilier, tapisserie... (1 400), muséologie (1500)... restent à étudier, comme Stella Melbye le fit pour le don Marcel Aubert. La faiblesse numérique de certains domaines, Préhistoire (150 plaques de verre), archéologie du Moyen-Orient (95 plaques de verre) ${ }^{77}$, art de l'Islam (480 plaques de verre), laisse supposer qu'une partie des clichés réalisés pour les professeurs notifiés et localisés au " département » dans les registres de commandes le sont toujours ${ }^{78}$.

Pour certains ensembles, les questions de l'origine et de la constitution se posaient, tel le fonds dénommé "Louvre OA », constitué de clichés d'architecture, de sculpture et d'arts décoratifs en Europe admirablement classés de l'époque paléochrétienne (fig. 27) à l'époque contemporaine. Des boîtes en bois remplies de plaques de verre et de diapositives entreposées dans des réserves du département des Objets d'art du Louvre complètent cette collection. 
Fig. 27

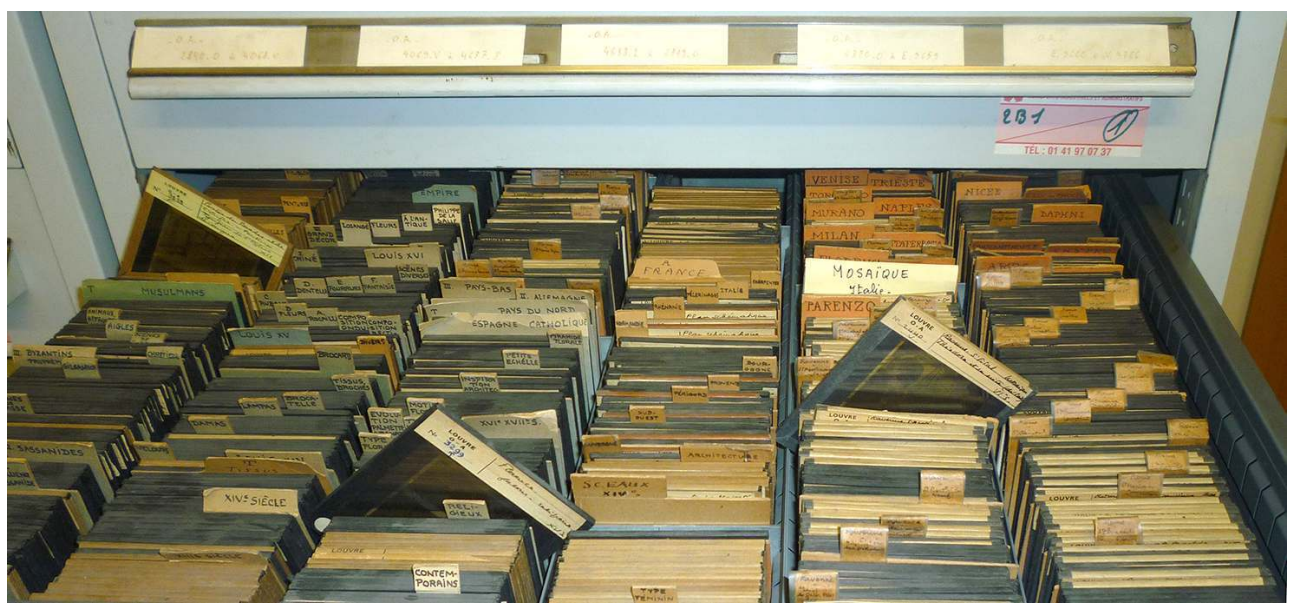

30 Fonds Louvre OA : classement dans les meubles métalliques Arch/EDL

\section{Négatifs}

31 Un nombre important de négatifs sur verre de petites dimensions $(5,7 \times 9$ et $9 \times 12)$ restait une énigme qui fut en partie résolue par la lecture des archives de $1944^{79}$. Une lettre du directeur des Musées nationaux, Jacques Jaujard, demandait à la secrétaire adjointe des Musées nationaux de lui dire si elle était entrée en possession des clichés qui avaient été retrouvés dans des caisses des réserves, vraisemblablement, du département des Peintures du Louvre ${ }^{80}$; l'inventaire en avait été commencé par $\mathrm{M}^{1 l e}$ Tissier pour ce qui concernait le département des Peintures et fut terminé à l'École. Le nombre de négatifs contenus dans des boîtes, d'une capacité approximative de 150 à 200 négatifs chacune, fut estimé à près de 5450 . Dans l'inventaire, un grand nombre de négatifs furent mis en relation avec les plaques de projection conservées à l'époque à la photothèque, et qui servirent pour les cours de peinture française dispensés les années précédentes par Bernard Dorival, conservateur au Musée national d'art moderne (près de 3000$)^{81}$ et de peinture étrangère par Michel Florisoone, conservateur à la chalcographie du musée du Louvre (1800 à 2000) ${ }^{82}$. S'y ajoutaient des négatifs d'archéologie, d'architecture et de sculpture (fig. 28). 


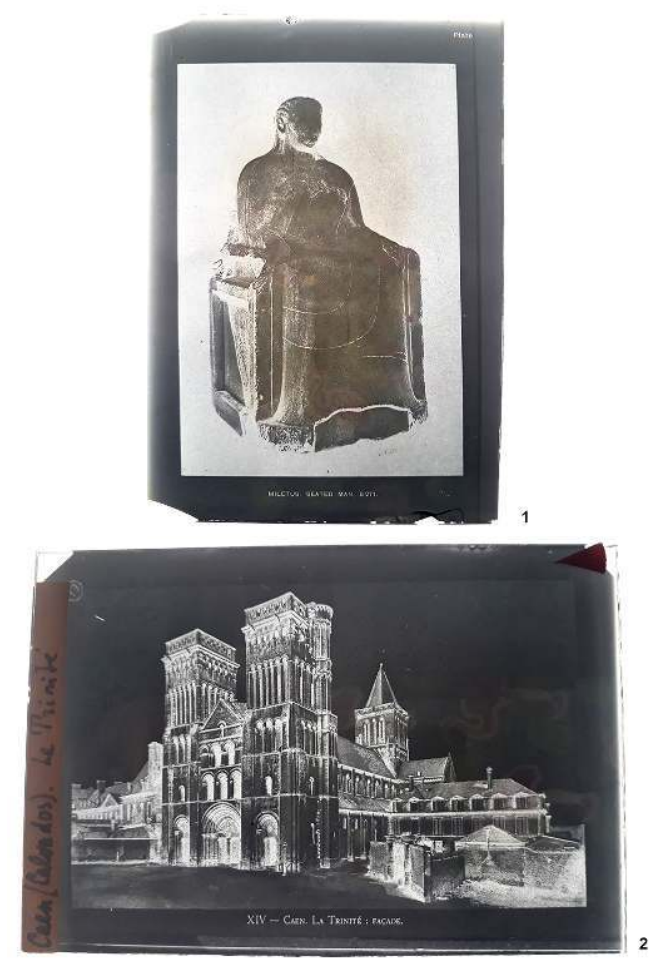

Négatif sur verre $(5 \times 7 \mathrm{~cm}): 1$. archéologie grecque, Milet, statue d'homme assis ; 2 . architecture médiévale, la Trinité de Caen

Arch/EDL

D'autres négatifs actuellement entreposés dans l'armoire métallique ont été accumulés au cours des déménagements, près de 2070 négatifs sous verre de formats différents et 490 souples. Un inventaire en a été dressé succinctement par les stagiaires du " chantier école». Les boîtes ont été numérotées et un bref descriptif reprend les informations inscrites sur le contenant et le type de document ${ }^{83}$. Des annotations précisent soit les donateurs, soit les enseignants qui les avaient utilisés. Ainsi note-t-on les dons de René Huyghe, conservateur au département des Peintures du musée du Louvre (146 négatifs : peinture, sculpture, gravure, Antiquité, art paléochrétien et byzantin) ; Germain Bazin, conservateur du département des Peintures et des Dessins (162 négatifs: architecture, sculpture, peinture); Charles Sterling, qui ne fit que quelques conférences à l'École (362 négatifs sur support souple et 7 plaques : peinture, enluminure, gravure) ; Michel Florisoone (99 négatifs de peinture italienne)...

Un registre d'inventaire (s. d.), conservé à la photothèque, pourrait correspondre au catalogage évoqué dans les correspondances entre le directeur des Musées nationaux et la responsable de la photothèque. Quelques sondages ont permis d'établir des concordances entre le numéro d'inventaire, le sujet et des plaques de verre en négatif, mal cadrées, prises d'après des ouvrages (fig. 29). Ces négatifs devaient servir au tirage d'épreuves en positif, comme les plaques de verre gélatino-argentique, pour certaines achetées auprès de sociétés spécialisées qui permettaient aux amateurs ou aux professionnels de fabriquer leurs propres diapositives sur verre. 


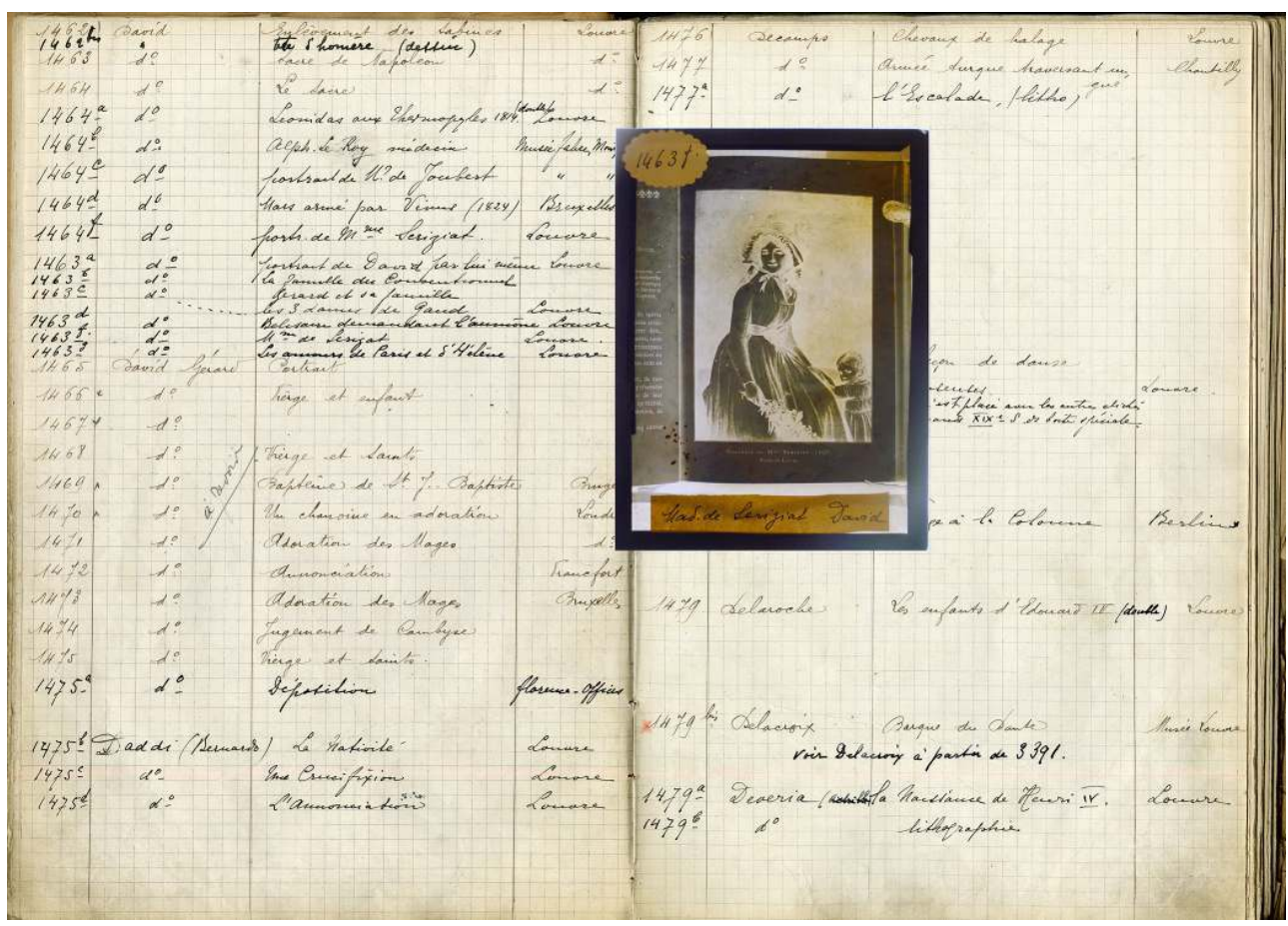

Registre de négatifs (sans date) : Portrait d'Émilie Sériziat et son fils, Jacques-Louis David, 1795, musée du Louvre

Arch/EDL

Ce fonds a été maintenu presque dans son intégralité grâce à une gestion rigoureuse transmise par les sources écrites, témoin d'un souci permanent de préserver un bien au service des enseignants.

\section{Gestion et organisation des plaques de verre 1938-1959}

\section{Fonctionnement}

Chaque année, les enseignants chargés de cours furent invités par le directeur des Musées nationaux et de l'École du Louvre puis par le directeur des études à communiquer leurs listes de clichés, transmises ensuite au personnel affecté à la documentation photographique. L'agent préposé effectuait des recherches dans le fonds documentaire puis procédait aux commandes pour les clichés manquants. En 1934, Pierre-Edmond Ladoué, conservateur adjoint du musée national du Luxembourg (1930-1938), adressa une liste manuscrite de clichés pour trois leçons d'histoire générale de l'art ${ }^{84}: 77$ peintures et sculptures $\mathrm{XIX}^{\mathrm{e}}$-début $\mathrm{XX}^{\mathrm{e}}$ siècle, classées par ordre alphabétique des auteurs, avec la référence des clichés au " Louvre » et aux « Archives » photographiques, rue de Valois (fig. 21). Trois jours avant son cours, déplorant les lacunes documentaires et l'absence de clichés d'œuvres incontournables, il informa qu'il serait obligé d'utiliser des cartes postales ou des photographies qu'il projetterait au moyen de l'appareil Dussaud pour les tableaux n'existant ni à la photothèque ni rue de Valois ${ }^{85}$. Parfois, des listes de clichés disponibles étaient transmises aux enseignants. En 1956, Suzanne Pierre Fallot fit parvenir à Simone Mollard-Besques, conservateur au 
département des Antiquités grecques et romaines du Louvre, une liste de 400 clichés disponibles pour son cours d'histoire générale de l'art de première année en archéologie grecque indiquant un état des collections à cette date ${ }^{86}$.

\section{Gestion du fonds} dispersion des plaques gardées dans les divers départements. La rédaction d'un inventaire devint indispensable pour la connaissance des clichés destinés à être prêtés à l'ensemble des enseignants et la justification des sommes allouées au fonctionnement de la photothèque et à la fabrication des supports pédagogiques. Henri Verne envoya début février 1938 un courrier à quinze enseignants pour leur demander de restituer au secrétariat de l'École les clichés photographiques qui auraient servi à illustrer leurs cours ou commandés à cette fin ${ }^{87}$. Tous les clichés seraient concentrés au service commercial dans les mains de $\mathrm{M}^{\text {me }}$ Bozzi, secrétaire technique à la direction des Musées nationaux, qui en dresserait un catalogue et gérerait les prêts en reportant les numéros de clichés dans un livre où les dates de sortie et de retour seraient indiquées ${ }^{88}$. Seul Louis Hautecœur, conservateur du musée du Luxembourg, répondit alors qu'il n'avait aucune plaque en sa possession ${ }^{89}$ !

La question de la «centralisation» des plaques de verre était toujours aussi préoccupante et la secrétaire générale de l'École, $\mathrm{M}^{\mathrm{me}}$ Pardo, alerta Jacques Jaujard en 1944 afin qu'il prît des mesures efficaces, tout en tenant compte de la nécessité de la proximité de cet outil de travail, indispensable aux enseignants qui souhaitaient être assurés d'en disposer pour leur cours. Deux propositions pour pallier la dissémination des clichés furent suggérées : la première par l'établissement d'un fichier en double exemplaire de collections conservées dans les départements, projet abandonné en raison de sa lourdeur; la seconde par la suppression du livre de prêt et son remplacement par un carnet de bordereaux établis en double exemplaire lors de l'emprunt. Une certaine discipline s'est instaurée ${ }^{90}$.

Des difficultés financières accrues en raison du coût des diapositives en couleurs, de l'achat d'un nouvel appareil de projection, des initiatives malencontreuses des enseignants conduisirent, en 1956, Georges Salles, directeur des Musées nationaux et de l'École du Louvre, à sermonner les conservateurs qui prenaient trop de libertés en gardant leurs clichés et passant commande directement à $\mathrm{M}$. Séarl, chef de l'atelier photographique des musées ${ }^{91}$, ou à des photographes extérieurs au Louvre ${ }^{92}$. Des bordereaux de « Demande de photographie à remettre au chef du service administratif de Musées de France pour le département : École du Louvre » furent établis avant de transmettre les documents à photographier par M. Séarl ${ }^{93}$. Cependant, Edmond Sidet, directeur des musées de France et de l'École du Louvre, alerta, deux années plus tard, Paul Deschamps, directeur des études, des irrégularités dans la comptabilité et la gestion financière de la photothèque: les crédits destinés à l'enrichissement des collections étaient détournés, et les clichés enregistrés fictivement étaient dispersés en " dépôt " chez les professeurs ${ }^{94}$. Sans désavouer Edmond Sidet, qui menaça de faire supprimer tout crédit d'achat de clichés, Paul Deschamps fit part d'une certaine solidarité à l'égard de ses confrères qui avaient, en raison de leurs responsabilités professionnelles, «besoin d'avoir leurs projections à portée de la main. Si j'avais leur âge avec quelques années d'enseignement devant moi, il est extrêmement probable que 
j'agirais comme eux »... et d'ajouter qu'en raison de leur rémunération dérisoire, il lui semblait légitime de leur faciliter la tâche ${ }^{95}$. Pour étayer le projet de lettre à l'adresse des enseignants, justifié par une augmentation croissante du nombre de cours et de conférences, et par là même de commandes et d'emprunts de clichés plus nombreux, le chef $\mathrm{du}$ service de la photothèque, Suzanne Pierre Fallot, rappela le règlement en vigueur, classant les cours en fonction de l'importance scientifique: 1. cours organiques, 2. histoire générale de l'art, 3. cours Rachel Boyer, 4. cours réservés aux élèves américains, 5. conférences en dehors de l'École. Aussi proposa-t-elle de déposer les clichés archéologiques très spécialisés dans les départements et de conserver les clichés d'Histoire générale de l'art à la photothèque, et évoqua la solution onéreuse d'avoir des clichés en double ou de fournir aux professeurs une épreuve papier pour leur documentation personnelle ${ }^{96}$. De nouvelles règles furent édictées reprenant la hiérarchisation des cours : les clichés des cours organiques pouvaient être prêtés à l'année et ceux correspondant à des découvertes récentes resteraient en possession des conservateurs jusqu'à leur publication, les autres étant restitués à la photothèque ${ }^{97}$.

Deux registres traduisent la rigueur de la gestion des clichés. Sur chaque page furent indiquées les dates de commande et de livraison: les délais d'exécution des travaux (fabrication, achat à préciser); le nombre de clichés, terme utilisé indifféremment pour les plaques de verre et les diapositives; le format $8 \frac{1 / 2}{2} \times 10$ ou $24 \times 36$; le prix à l'unité en anciens francs/nouveaux francs à partir de janvier $1959^{98}$; le demandeur ; le sujet du cours ; l'identité du cliché ; le numéro d'enregistrement au catalogue ; la localisation des clichés emportés dans les départements (fig. 20 et 30).

Fig. 30

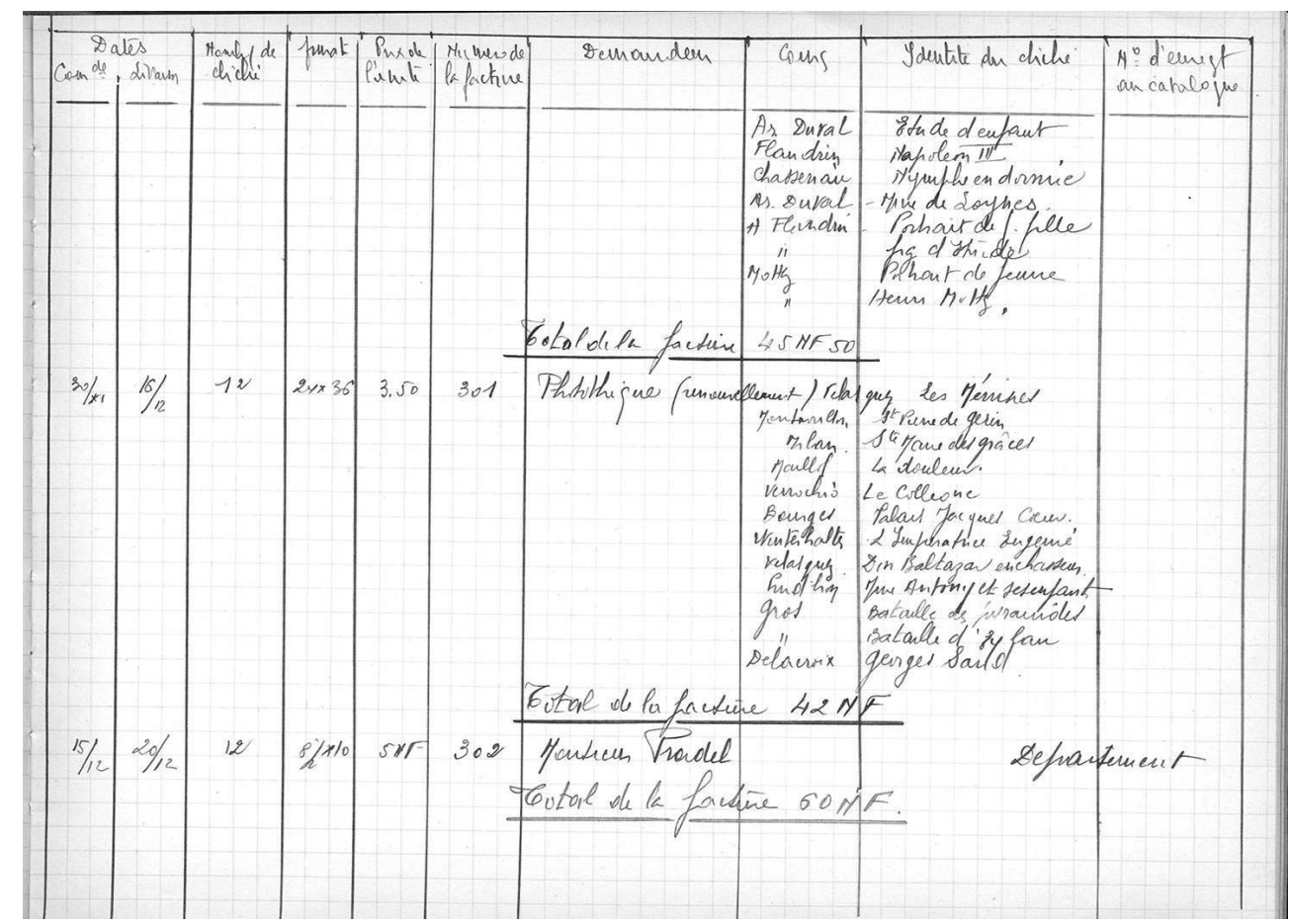

Registre de commandes et prêts : dernière commande de clichés 8 1⁄2 le 20 décembre 1960 par Pierre Pradel

Arch/EDL 


\section{Organisation des clichés}

39 À l'origine, les clichés étaient catalogués sommairement; à partir de 1938, un fichier scrupuleusement tenu à jour fut établi et à chaque plaque numérotée correspondait une fiche. En 1940, $\mathrm{M}^{\text {me }}$ Pardo, secrétaire adjointe de l'École du Louvre, réorganisa les collections pour faciliter les recherches documentaires et le classement des plaques. Chaque année, au cours de l'été, elle procédait avec une collaboratrice au récolement en confrontant fiche et plaque, les nouveaux clichés de cours de l'année précédente étaient catalogués et numérotés, ceux détériorés restaurés ${ }^{99}$.

Un système de numérotage simple fut adopté pour procéder au regroupement des clichés par artistes, époques, lieux... et permettre une notation fidèle des clichés empruntés et une vérification efficace.

Un "plan du catalogue des clichés d'architecture» laisse paraître une certaine complexité que devait clarifier l'organisation des fiches dans les tiroirs. La classification se structure comme suit: par Pays, 1. période - architecture "préromane", architecture romane, architecture gothique, architecture Renaissance, architecture $d u \mathrm{xvII}^{\mathrm{e}}$ siècle...; 2. fonction de l'édifice - architecture monastique, architecture militaire, architecture civile; 3. régions, localités; puis les ensembles étaient regroupés par vue d'ensemble extérieure, vue d'une partie de l'extérieur, détails des parties extérieures, vue de l'intérieur, détails de l'intérieur... et enfin le numérotage de 01 à X (fig. 24 et 25). En parallèle, des fiches cartonnées manuscrites et d'autres dactylographiées avec un numéro de classement et une brève description furent établies et rangées dans des tiroirs, vraisemblablement par lieux, pour retrouver ensuite les plaques disposées dans des boîtes. Actuellement, les fiches sont conservées, celles de peinture, art graphique classées par pays et auteurs furent regroupées dans des tiroirs métalliques, celles d'archéologie et de muséologie rangées avec les fiches des diapositives, reflétant ainsi l'ensemble de la documentation sur une œuvre, un lieu, un musée. Il en était de même des fiches des plaques architecture et sculpture, qui récemment ont été réunies dans un ordre aléatoire dans les fichiers métalliques.

41 L'engouement pour les collections de plaques de verre, longtemps menacées, qui dorénavant prennent une valeur de collection patrimoniale, digne d'étude, confortée par des rencontres scientifiques ${ }^{100}$ et des expertises, conduit parfois à négliger un autre médium présent dans toutes les mémoires et qui fut au service de l'enseignement : la diapositive. Des « désherbages » intempestifs détruisent des collections qui retracent près de soixante ans de pratiques pédagogiques, l'état d'un patrimoine, en fonction de critères aléatoires inscrits dans des protocoles accompagnés de procédures. Pour préserver les collections photographiques argentiques après leur numérisation, un appel émanant de conservateurs, archivistes, historiens d'art et chercheurs en sciences humaines a été lancé sous l'égide de Constanza Caraffa ${ }^{101}$ pour sensibiliser les gestionnaires de collections photographiques. Les préconisations sont d'ordre technique et scientifique. L'archive numérique ne peut se substituer à l'argentique, car la conservation des données numériques n'est pas maîtrisée ${ }^{102}$; l'archive numérisée résulte d'une sélection et d'une réduction, alors que la mission fondamentale des archives photographiques est de garantir l'intégrité de la documentation historique, sa conservation et sa valorisation pour permettre aux générations futures des travaux tels que ceux menés aujourd'hui, avec passion, sur les plaques de verre. 


\section{NOTES}

1. Monique Laurent, «L'École du Louvre, 1932-1962 : ses méthodes, ses résultats ", mémoire de recherche approfondie (thèse EDL), sous la direction de Jean Chatelain, 1967 ; Sophie Picot, «Les premières années de l'École du Louvre, 1882-1914 ", mémoire de Maîtrise, Histoire contemporaine, sous la direction de Pascale Ory, université de Paris I - Panthéon-Sorbonne, octobre 2000.

2. Gaston Brière, «L'enseignement de l'histoire de l'art en France. École du Louvre », dans Revue de Synthèse Historique, 1914, t. 28, p. 54 ; Henri Verne, Edmond Pottier, Alfred Merlin et al., L'École du Louvre, 1882-1932, Paris, Bibliothèque de l'École du Louvre, 1932 ; Monique Laurent, « Historique de l'École du Louvre ", Musées et collections publiques de France, $n^{\circ} 105$ (Nouvelle Série) n 57, 1968 $\mathrm{n}^{\circ}$ 4, pp. 195-200 ; S. Picot, «Les premières années de l'École du Louvre, 1882-1914 », Histoire de l'art, avril 2005, n 56, pp. 101-109.

3. Les archives de l'École du Louvre ont été versées partiellement aux Archives des musées nationaux (AMN), puis aux Archives nationales, Inventaire Série FF - fr/FRDAFAN/ 20150334/1-20150334/100 (AN/AMN F 21).

4. Les archives de la photothèque (Arch/EDL) conservées dans les services documentaires, composées de notes, correspondances, factures, listes de clichés, registres d'inventaire et registres de commandes et prêts, couvrent la période 1934-1961 et complètent le fonds des Archives nationales.

5. Henri Verne, «Le plan d'extension et le regroupement méthodique des collections du musée du Louvre. Les travaux de 1927 à 1934 ", Bulletin des Musées de France, 1934-01, janvier 1934, pp. 1-41.

6. Id., Ibid., p. 10.

7. Id., Ibid., p. 17.

8. Arch/EDL 26 juin 1938 : Rapport de $\mathrm{M}^{\text {me }}$ Oberlander, chargée de mission des musées nationaux, sur l'importance de la clichothèque.

9. Les meubles étaient placés dans un réduit jouxtant au sud l'estrade de l'amphithéâtre Courajod. On y accédait par une porte dérobée ouverte dans la base de l'estrade.

10. Fichier Excel.

11. À partir de 1992, une partie du fonds (environ 900 sur 2040 clichés) a été numérisée et indexée sur la base " Micromusée ", base de données utilisée alors par de nombreux musées, puis transférée sur la base de données « Ariane ». Les images n'ont pas été versées dans PLEIADES. En noir et blanc, elles ont été jugées de médiocre qualité pour une base qui se veut de prestige.

12. François Mazéas, agent de la Réunion des musées nationaux.

13. Jean-Daniel Pariset.

14. La MAP a pour mission de collecter, conserver, étudier et valoriser deux grands ensembles : les archives et la documentation de l'administration des Monuments historiques d'une part, et le patrimoine photographique de l'État de l'autre.

15. Alors archiviste au ministère de la Culture.

16. Anne de Mondenard, responsable scientifique à la mission de la photographie.

17. Denis Christophel, « Henry de Lestrange, un photographe amateur autour de 1900 ", sous la direction de Jean-François Chevrier, Paris, École nationale des beaux-arts, décembre 2012 https://www.fichier-pdf.fr/2012/12/13/memoire/

18. Stage organisé du 21 au 25 mai 2012 dans le cadre de la formation des élèves conservateurs et restaurateurs du patrimoine et de celle des régisseurs de l'École du Louvre. Thématique: conservation-restauration. 
19. Rapport du chantier-école de la photothèque de l'École du Louvre, rédigé par Sophie Quévillon, Sarah Ligner, Stéphanie Mahieu, Isabelle Jonc, élèves conservateurs ; Chloé Lucas, Elsa Thyss, Ewa Smielecka, élèves restaurateurs; Claire-Lise Huet, Suzanne Stemmer, élèves régisseurs, sous la direction de Giulia Cuccinella, restauratrice de photographies, enseignante au département des restaurateurs de l'INP, 21-25 mai 2012, 76 p.

20. Boîte 360, M. Chambon, étagère 5.

21. Technique basée sur l'emploi de particules colorées de fécule de pomme de terre teintées en orangé, violet et vert déposées en couche unique sur une lame de verre, puis recouvertes d'un vernis et d'une couche d'émulsion sensible. Auguste et Louis Lumière sont les premiers à proposer un procédé fiable et relativement simple de restitution de la couleur : l'autochrome. Ils expliquent leur méthode le 30 mai 1904 à l'Académie des sciences.

22. Bruno Le Namouric, Gaël Quintric, Bertrand Sainte-Marthe, conservateurs-restaurateurs du patrimoine photographique, 22, 23 juin et 2 août 2012 : "Elles ont été époussetées à la brosse à mèche souple. L'émulsion a ensuite été dépoussiérée avec un coupon de textile microfibre. Le verre des clichés a été nettoyé avec des embouts de coton imprégné d'une solution eau/éthanol. Les clichés fêlés ou dont l'émulsion est soulevée, ont été doublés d'une lame de verre appliquée sur l'émulsion, assemblée au cliché par du film adhésif synthétique transparent Permacel J-Lar. Seize clichés $18 \times 24$ et 20 clichés $24 \times 30$ ont ainsi été doublés en raison de soulèvement de l'émulsion. Après leur dépoussiérage, nettoyage et/ou consolidation, les clichés ont été insérés sous enveloppe individuelle à quatre rabats en papier de Chronos, sur laquelle les informations relatives à leur classement ont été reportées au crayon. Les clichés ont ensuite été installés dans des boîtes de conservation pHibox Duo modèle PV de Stouls. "

23. Cours soutenus par la fondation d'entreprise Neuflize Vie.

24. Stella Melbye, «La reproduction photographique : un outil et un argument dans l'histoire de l'art. L'analyse du fonds de plaques de projection de Marcel Aubert (1884-1962) situé dans la photothèque de l'École du Louvre ", mémoire d'étude (M1), sous la direction de Dominique de Font-Réaulx et Anne-Bénédicte Mérel-Brandenburg, École du Louvre, 2013.

25. Arnaud Pedersen.

26. Protégées par des pochettes à rabats, papier neutre et numérotées.

27. Charles Roux.

28. AN/AMN F 21, 16 avril 1912, Note d'André Michel relative au fonctionnement de l'École du Louvre ; cours d'Histoire de la sculpture, projet d'une bibliothèque.

29. AN/AMN F 21, 7 juillet 1888, Rapport d'Edmond Pottier au directeur.

30. Louis Courajod, Alexandre Lenoir, son journal et le musée des Monuments français, I, Paris, H. Champion, 1878, p. CLX.

31. AN/AMN F 21. En 1901 furent exposées les planches du livre d'Adolf Furtwängler et Heinrich Ludwig Urlichs, Denkmäler Griechischer und Römischer Sculptur, Munich, Brunn-Bruckmann's, 1898.

32. AN/AMN F 21, Courrier du 6 novembre 1888.

33. Salomon Reinach, Apollo, Histoire générale des arts plastiques, Paris, Hachette, 1904, in-12², xi-335p. Dédié par l'auteur « à mes auditrices de l'École du Louvre (1902-1903) », préface, p. X.

34. AN/AMN 1907, Cours d'Histoire de la Peinture de Salomon Reinach, Affluence des élèves et auditeurs, Pétition des élèves et auditeurs réclamant une salle plus grande, Délivrance des cartes d'élèves, Autorisation de disposer de la galerie Denon pour le cours, Frais d'installation du cours. 35. Guillaume Foucher, « Méthodes pédagogiques de Louis Courajod à l'École du Louvre ", dans Un combat pour la sculpture. Louis Courajod (1841-1896). Historien d'art et conservateur, Paris, École du Louvre, coll. « Rencontres de l'École du Louvre », 2003, p. 106.

36. AN/AMN, série F22, 0144781/1-20144781/37-20144781/22, Matériel et dons de livres, 15 janvier 1889.

37. Archives nationales, Archives des musées nationaux F21 20144781/22.

38. S. Picot, op. cit. note 1, p. 118. 
39. Florent Miane, «Les plaques à projection du musée archéologique de l'université de Bordeaux. Différences et évolution des usages entre le support papier et l'image projetée ", Plaques photographiques, fabrication et diffusion du Savoir, colloque international organisé par Denise Borlée et Hervé Doucet, Institut d'histoire de l'art, université de Strasbourg, 16-18 mars 2016, https://www.canal-u.tv/video/uds/

les_plaques_a_projection_du_musee_archeologique_de_l_universite_de_bordeaux_differences_et_evolution_des_usages_entre_le_sup 21517 (mn 17'23).

40. La maison Radiguet, fondée par Marie-Honoré Radiguet (1791-1867), était spécialisée dans la fabrication et la vente d'appareils d'optique depuis 1830. Le 6 octobre 1899, Radiguet fils s'associa avec son gendre, Georges Massiot (1875-1962), pour former la société en nom collectif Radiguet et Massiot.

41. AN/AMN F22, 23 octobre 1913, Juliare fournit une grille de cuivre.

42. AN/AMN F22, 11 juin 1921, demande de modification de l'appareil de projection ; 17 décembre 1921, modification de l'appareil de projection.

43. AN/AMN F22, 5 mars 1922.

44. AN/AMN F22, 12 mars1925.

45. AN/AMN F22, 22 février 1938.

46. AN/AMN F22, 21 octobre 1938.

47. H. Verne, op. cit. note 5, p. 17.

48. Arch/EDL, 26 juin 1956.

49. Nouvelles salles.

50. Arch/EDL, 26 juin 1938, Rapport sur la clichothèque.

51. Félix Martin-Sabon a travaillé bénévolement pour la commission des Monuments historiques pendant plus de quarante ans. AN/AMN, 21 janvier 1903.

52. AN/AMN F22, 7 juin 1928.

53. Les boîtes 1 à 19 contiennent des clichés d'archéologie (172); 20 à 30 : peinture romaine et byzantine ( 66 clichés) ; 31 à 47 : miniatures $(117) ; 48$ à 54 : peinture française de François I ${ }^{\mathrm{er}}$ par Clouet à l'olympia de Manet (167); 58 à 59 : architecture européenne ; 60 : peinture anglaise (6 clichés); 61 à 66 : peinture espagnole illustrée par Murillo et Vélasquez (64); 67 à 69 : mobilier $\mathrm{XVIII}^{\mathrm{e}}$ siècle ; 70 à 153 : peinture flamande, hollandaise, allemande, du Retable de l'Agneau mystique de van Eyck au Char du Soleil du Maître ES (840); 153 à 307 : peinture italienne, des Combats de nus de Pollaiolo à la Sainte Cécile de Dolci (1534).

54. AN/AMN F22, 12 décembre1933.

55. AN/AMN F22, 4 juillet 1960.

56. AN/AMN F22, 15 mars 1922 ; 1926 ; 22 juin 1928, Guillaume Janneau, cours d'histoire des techniques ; 27 novembre 1930.

57. Séraphin-Médéric Mieusement fonda une maison d'édition photographique en 1863, et passa un accord avec la commission des Monuments historiques, contrat qui lui concédait l'exploitation commerciale d'une partie des clichés des Monuments historiques. En 1890, il céda sa concession de photographe des Monuments historiques à son gendre Paul Robert.

58. S. Picot, op. cit. note 1, p.118; AN/AMF F22, 17 janvier 1913.

59. Arch/EDL, 23 avril 1934, Leçons de M. Ladoué.

60. Arch/EDL, mars 1939, 10 clichés sur la Rome baroque.

61. Arch/EDL, 23 février 1938.

62. Arch/EDL, 24 octobre 1938.

63. Arch/EDL, 7 et 13 février 1957, Courrier de $M^{\text {me }}$ Barrelet, accompagné de la liste des clichés à prendre dans des ouvrages et dans les salles.

64. Arch/EDL, 21 janvier 1944.

65. Maison Bulloz 15 frs + $12 \%$; Maison Massiot 15 frs + $12 \%$; Séarl (photographe Louvre) 13 frs. 
66. Arch/EDL, 15 janvier 1945, Louis Gillet, Projet d'acquisition d'une collection de clichés. Correspondance du 14 avril 1945.

67. Arch/EDL, 16 août 1947, Lettre manuscrite de $\mathrm{M}^{\text {me }}$ Doumic-Gillet ; 2 septembre 1947.

68. Arch/EDL, 2 février 1954, Courrier dactylographié de la secrétaire de l'École du Louvre à $\mathrm{M}^{\text {lle }}$ Rocheblave ; 9 février 1954, Réponse de $\mathrm{M}^{\text {lle }}$ Rocheblave et liste jointe. 108 doubles.

69. Arch/EL, 26 juin 1956, Lettre de la secrétaire de l'École du Louvre ( $\mathrm{M}^{\mathrm{me}}$ Vinès) à Monsieur le directeur des Musées de France.

70. Arch/EDL, Correspondance 3 juillet 1956.

71. Depuis le décret du 25 juillet 1882, l'administrateur du Louvre est nommé directeur des musées de France et de l'École du Louvre.

72. La liste de sa commande de 80 clichés en couleurs est conservée : «Clichés en couleur à faire prendre au musée des monuments français par les soins de Madame Vinès ».

73. Enseignement : 1941-1965.

74. Novembre 1956 à décembre 1957.

75. 3 décembre 1958-20 décembre 1959.

76. Stella Melbye a identifié les photographies prises par Marcel Aubert.

77. Registre de commande et prêt 1956-1957 ; Arch/EDL, 7 et 13 janvier 1957, $\mathrm{M}^{\text {me }}$ Barrelet et M. Parrot firent des demandes régulières de clichés en 1957.

78. Ces registres répertorient de nombreuses commandes qui pourraient servir de base à un récolement et aux contenus des cours.

79. Arch/EDL, 21 janvier 1944.

80. Arch/EDL, 21 janvier 1944, l'emplacement des réserves n'est pas précisé.

81. Une boîte pour les peintres provinciaux, une autre pour Philippe de Champaigne, une pour La Tour, Le Valentin, les Le Nain et leur école, une pour Le Brun, Mignard, Lesueur, peintres officiels, une pour Claude Le Lorrain, une pour Poussin, et une dernière de natures mortes et divers.

82. Peinture italienne : aux huit boîtes de peinture vénitienne s'ajoutent une boîte «École du nord de l'Italie » rattachée à Venise, environs 1500 négatifs et 2 boîtes « École italienne divers ", plus spécialement Renaissance florentine, Léonard de Vinci et école romaine. Deux autres boîtes, soit près de 300 à 400 négatifs de peinture internationale.

83. Une analyse plus poussée incite à la prudence: le contenu ne correspond pas systématiquement aux indications portées sur les boîtes.

84. Arch/EDL, 17 ou 18 avril 1934.

85. Arch/EDL, 23 avril 1934.

86. Arch/EDL, 14 novembre 1956.

87. Arch/EDL, 23 février 1938, Gaston Brière (Versailles), Louis Hautecœur (Luxembourg), Georges Contenau (antiquités orientales), Charles Boreux (antiquités égyptiennes), Jean Charbonneaux, Charles Mauricheau-Beaupré (Versailles), Alfred Merlin (AGER), André Parrot (antiquités orientales),Gabriel Rouchès (dessins chalcographie), Robert Rey (inspecteur général, rue de Valois), M. Fontaine (objets d'art), Georges Salles, Paul Vitry (sculpture).

88. Arch/EDL, 23 février 1938, Lettre dactylographiée du directeur des Musées nationaux et de l'École du Louvre.

89. Arch/EDL, 25 février 1938.

90. Arch/EDL, 29 janvier 1944, Rapport sur l'état des collections de clichés de l'École du Louvre, par la secrétaire adjointe de l'École du Louvre au directeur des Musées nationaux et de l'École du Louvre.

91. Arch/EDL, 26 juin 1956 ; 7 septembre 1956.

92. Arch/EDL, 30 janvier 1958, parvient au nom de la photothèque une facture de « cine photo » correspondant à une commande passée directement par $\mathrm{M}^{\mathrm{me}}$ Desroches Noblecourt, conservateur au département des Antiquités égyptiennes. 
93. Arch/EDL, 2 novembre 1956 ; janvier 1958.

94. Arch/EDL, 7 novembre 1958.

95. Arch/EDL, 14 novembre 1958.

96. Arch/EDL, 18 novembre 1958.

97. Arch/EDL, 26 novembre 1958.

98. Prix des plaques et des diapositives : $8 \frac{112}{2} \times 10: 500 \mathrm{AF} ; 24 \times 36: 350 \mathrm{AF} ; 5 \times 5: 360 \mathrm{AF}$.

99. Arch/EDL, 29 janvier 1944.

100. Plaques photographiques, fabrication et diffusion du Savoir, colloque international organisé par Denise Borlée et Hervé Doucet, Institut d'histoire de l'art, université de Strasbourg, 16-18 mars 2016.

101. Chef de la photothèque du Kunsthistorisches Institut à Florence http://www.khi.fi.it/it/ Declaration

102. Question non résolue du caractère éphémère et de l'instabilité des formats numériques, avec tous les problèmes technologiques et structurels associés.

\section{RÉSUMÉS}

L'École du Louvre conserve au sein des services documentaires, regroupé dans les espaces de la photothèque, un fonds iconographique composé de photographies, de cartes postales, de plaques de verre positives et négatives, de formats différents, noir et blanc, autochromes, de négatifs sur support celluloïd et de diapositives, supplantés depuis les années 1995 par le numérique. Au-delà de la patrimonialisation de cet ensemble exceptionnel destiné à l'enseignement, l'article se concentrera à partir des archives écrites mises en perspective avec la collection de plaques de verre sur ses pérégrinations (1932-2005), sa genèse et sa constitution, sa gestion et sa classification (1900-1960), et sur le regain d'intérêt dans les années 2010. La richesse du corpus offre ainsi des sujets d'études inédits, de l'histoire de la photographie à une approche pluridisciplinaire : peinture, sculpture, arts décoratifs, archéologie, muséologie, pédagogie.

The École du Louvre holds, in the spaces of its photographic library, an iconographic collection made up of photographs, postcards, positive and negative glass plates in various sizes, black and white, autochromes, celluloid negatives and slides, supplanted by digital in 1995. Beyond the patrimonialisation of this exceptional collection intended for teaching, the article will focus, based on written archives put into perspective with the glass-plate collection, on its peregrinations (1932-2005), genesis and constitution, management and classification (1900-60), and the renewed interest in the 2010s. The richness of the corpus thus offers new objects of study, from the history of photography to a multidisciplinary approach: painting, sculpture, decorative arts, archaeology, museology and pedagogy.

\section{INDEX}

Mots-clés : plaques de verre, École du Louvre, enseignement, photographie

Keywords : glass plates, École du Louvre, teaching, photography 


\section{AUTEUR}

\section{ANNE-BÉNÉDICTE MÉREL-BRANDENBURG}

Membre de l'équipe de recherche de l'École du Louvre, Anne-Bénédicte Mérel-Brandenburg, fut longtemps chargée de collections documentaires à la photothèque de l'École et assura l'intérim du service. Elle est spécialisée en archéologie de l'Antiquité tardive et du haut Moyen Âge, plus particulièrement en France méridionale, de « l'archéologie funéraire et la culture matérielle en Languedoc méditerranéen » (DEA), à « La sculpture de l'Antiquité tardive et du haut Moyen Âge en Languedoc méditerranéen et Roussillon » (thèse Paris IV-Sorbonne, 2007). Elle a dirigé des chantiers de fouilles archéologiques, monté un programme de recherche sur les matériaux et publié les résultats de ses recherches. En 2017, elle a initié un programme de Corpus numérique de la sculpture de l'Antiquité tardive et du haut Moyen Âge, un partenariat entre l'École du Louvre, le département des Sculptures du Louvre et le CNRS (UMR 5138 Archéométrie et Archéologie; ARTEHIS UMR 6298). À l'École du Louvre, elle a enseigné l'Histoire de l'architecture occidentale, Antiquité tardive et haut Moyen âge (CS 1989-2005), l'Archéologie de la Gaule romaine (2014-2017-CO-CS) et encadré les travaux pratiques en Archéologie de la Gaule et du premier Moyen âge (2008-2016).

$* * *$

A member of the École du Louvre research team, Anne-Bénédicte Mérel-Brandenburg, was long in charge of the documentary collections of the school' photographic library and deputised for the department. She is a specialist in the archaeology of Late Antiquity and the Early Middle Ages, particularly in southern France, from "L'archéologie funéraire et la culture matérielle en Languedoc méditerranéen" (DEA), to "La sculpture de l'Antiquité tardive et du haut Moyen Âge en Languedoc méditerranéen et Roussillon" (thesis Paris IV-Sorbonne, 2007). She has overseen archaeological excavations, founded a research programme about materials and published the results of her research. In 2017 she initiated the programme Corpus Numérique de la Sculpture de l'Antiquité Tardive et du Haut Moyen Âge, a partnership between the École du Louvre, the Department of Sculptures of the Louvre and the CNRS (UMR 5138 Archéométrie et Archéologie; ARTEHIS UMR 6298). At the École du Louvre, she has taught the history of Western architecture, Late Antiquity and the Early Middle Ages (CS 1989-2005) and the archaeology of Roman Gaul (2014-2017-CO-CS), and has supervised seminars in the archaeology of Gaul and the Early Middle Ages (2008-16). 